\title{
THE
}

\section{Biological control of the vernal population increase of Calanus finmarchicus on Georges Bank}

Xingwen Li

Dennis J. McGillicuddy Jr.

Edward G. Durbin

University of Rhode Island

Peter H. Wiebe

Follow this and additional works at: https://digitalcommons.uri.edu/gsofacpubs

This is a pre-publication author manuscript of the final, published article.

Creative Commons License

(c) (i) $\Theta$

This work is licensed under a Creative Commons Attribution-Noncommercial-No Derivative Works 4.0 License.

\section{Citation/Publisher Attribution}

Li, X., McGillicuddy, D. J., Jr., Durbin, E. G., \& Wiebe, P. H. (2006). Biological control of the vernal population increase of Calanus finmarchicus on Georges Bank. Deep Sea Research Part II: Topical Studies in Oceanography, 53(23-24), 2632-2655. doi: 10.1016/j.dsr2.2006.08.011

Available at: https://doi.org/10.1016/j.dsr2.2006.08.011

This Article is brought to you for free and open access by the Graduate School of Oceanography at DigitalCommons@URI. It has been accepted for inclusion in Graduate School of Oceanography Faculty Publications by an authorized administrator of DigitalCommons@URI. For more information, please contact digitalcommons-group@uri.edu. 


\title{
Biological control of the vernal population increase of Calanus finmarchicus on Georges Bank
}

\author{
Xingwen Li ${ }^{1}$, Dennis J. McGillicuddy, Jr. ${ }^{1}$ (corresponding author) \\ Edward G. Durbin ${ }^{2}$, Peter H. Wiebe ${ }^{1}$ \\ Manuscript revised and resubmitted to Deep Sea Research II
}

March 14, 2006

${ }^{1}$ Woods Hole Oceanographic Institution, Woods Hole, MA 02543, USA. Tel: 508-289-2683, Fax: 508-457-2194, Email: dmcgillicuddy@whoi.edu [Corresponding Author]

${ }^{2}$ Graduate School of Oceanography, University of Rhode Island, South Ferry Rd, Narragansett, Rhode Island 02282, USA 


\begin{abstract}
An adjoint data assimilation approach was used to quantify the physical and biological controls on Calanus finmarchicus $\mathrm{N}_{3}$ to $\mathrm{C}_{6}$ stages on Georges Bank and its nearby environs. The mean seasonal cycle of vertically-averaged distributions, from 5 years of the GLOBEC Georges Bank Broad-Scale Surveys between January and June, was assimilated into a physical-biological model based on the climatological circulation. Large seasonal and spatial variability is present in the inferred supply sources, mortality rates, computed molting fluxes, and physical transports. Estimated mortalities fall within the range of observed rates, and exhibit stage structure that is consistent with earlier findings. Inferred off-bank initial conditions indicate that the deep basins in the Gulf of Maine are source regions of early-stage nauplii and late-stage copepodids in January. However, the population increase on Georges Bank from January to April is controlled mostly by local biological processes. Magnitudes of the physical transport terms are nearly as large as the mortality and molting fluxes, but their bank-wide averages are small in comparison to the biological terms. The hypothesis of local biological control is tested in a sensitivity experiment in which upstream sources are set to zero. In that solution, the lack of upstream sources is compensated by a decrease in mortality that is much smaller than the uncertainty in observational estimates.
\end{abstract}

Key words: Calanus finmarchicus; population dynamics; Georges Bank; inverse modeling; adjoint method 


\section{Introduction}

Calanus finmarchicus is a key zooplankton species in the Georges Bank (GB)/Gulf of Maine (GOM) ecosystem, and is an important food source for larval stages of commercially important fish species. Its life history is multifaceted (Carlotti, 1996), including hatching from eggs, development through 6 naupliar stages $\left(\mathrm{N}_{1}-\mathrm{N}_{6}\right)$ and 5 copepodid stages $\left(\mathrm{C}_{1}-\mathrm{C}_{5}\right)$, nonobligatory diapause, and maturation to adulthood $\left(\mathrm{C}_{6}\right)$. Large seasonal variability is present in the annual cycle of the C. finmarchicus population on GB (e.g., Davis, 1987). This species dominates the zooplankton biomass on the bank in spring/early summer, but is almost absent from the Crest of the bank from fall to the start of winter. Models have been used to elucidate aspects of the population dynamics of C. finmarchicus (Lynch et al., 1998; Miller et al., 1998; Tittensor et al., 2003; Zakardjian et al., 2003; Speirs et al., 2005; Johnson et al., this volume), but the processes controlling the annual population cycle remain enigmatic. In particular, the relative roles of recruitment, development, mortality, and physical transport have yet to be quantified in a systematic and spatio-temporally explicit manner. Such knowledge is not only important to evaluate the role of $C$. finmarchicus in the food web, but also to predict the consequences of climatic change on this organism (Hirche, 1996).

Abundance and distribution patterns of $C$. finmarchicus populations in the region are strongly influenced by physical mechanisms. The physical environment is complex (e.g., Bigelow 1927; Flagg, 1987; Butman et al., 1987; Lynch et al., 1996; Gangopadhyay et al., 2003). North of GB is the GOM, comprising three deep basins: Jordan Basin, Wilkinson Basin, and Georges Basin. South of GB is the continental slope and the Slope Water. To the west, GB is separated from Nantucket Shoals by the Great South Channel; to the northeast, it is separated from the Scotian Shelf by the Northeast Channel. The bank itself consists of distinctive 
subregions, such as the Northern Flank, the Northeast Peak, the Southern Flank, and the Crest (Figure 1). The mean circulation in the GOM/GB area is dominated by counter-clockwise flow along the perimeter of the basin, cyclonic gyres over the deep basins, clockwise circulation around GB, inflow through the Northeast Channel, and outflow via the western edge of the Southern Flank (Beardsley et al. 1997).

Observations from the GLOBEC (Global Ocean Ecosystem Dynamics) Georges Bank broad-scale surveys (Figure 1) provide an opportunity to investigate the physical and biological mechanisms controlling the population dynamics of $C$. finmarchicus. Our approach is to compute a monthly stage-based climatology from these observations, and to assimilate these data into a physical-biological model based on the climatological hydrodynamics of the region (Lynch et al., 1996). The inverse problem (schematized in Figure 2) is formulated by specification of the velocity and diffusivity fields, observed monthly distributions on Georges Bank, and development rates that depend on temperature and the availability of food (Campbell et al., 2001). The adjoint method is used to infer stage-based mortality fields, off-bank initial conditions, and sources of the youngest stage resolved by the model $\left(\mathrm{N}_{3}\right)$. Solutions resulting from the inversion procedure are then diagnosed to quantify physical and biological controls on the climatological abundance and distribution of $C$. finmarchicus on Georges Bank.

\section{Methods}

\subsection{Observations}

C. finmarchicus observations were derived from samples collected by plankton pumps (Durbin et al., 2000a) for $\mathrm{N}_{3}-\mathrm{C}_{1}$ and the Multiple Opening and Closing Net and Environmental Sensing System (MOCNESS, Wiebe et al., 1985) for $\mathrm{C}_{2}$ to $\mathrm{C}_{6}$ during GLOBEC Georges Bank 
broad-scale surveys from January to June between 1996-1999, and from February to June in 1995 (Durbin et al., 2000b). Monthly climatological values for each station (Figure 1) were obtained by averaging the observations over the five year period. Climatological values were then objectively analyzed (Hendry and He, 2002) to construct spatial maps.

Monthly climatological distributions for each C. finmarchicus stage (Figure 3) form the basic dataset for the inverse modeling. In January, a substantial number of nauplii were present on the bank. The age composition (Figure 4a) showed numbers of $\mathrm{N}_{3}>\mathrm{N}_{4}>\mathrm{N}_{5}>\mathrm{N}_{6}>\mathrm{C}_{1}$ $>\mathrm{C}_{2}>\mathrm{C}_{3}$, indicating the onset of reproduction. Relatively high abundances of $\mathrm{N}_{3}$ and $\mathrm{N}_{4}$ appeared in the north portion of the bank, with the maximum abundance center of $\mathrm{N}_{5}$ shifted toward the Northeast Peak. Abundances of $\mathrm{C}_{1}$ to $\mathrm{C}_{3}$ were very low on the bank; nauplii had not developed into these stages on the bank in January. Abundances of $\mathrm{C}_{4}, \mathrm{C}_{5}$ and $\mathrm{C}_{6}$ were higher than those of $\mathrm{C}_{2}$ and $\mathrm{C}_{3}$, implying that the majority of the animals in these later stages belonged to a prior generation. $\mathrm{C}_{5}$ and $\mathrm{C}_{6}$ abundances were relatively high near the Northern Flank.

In February, abundances of all stages except for $\mathrm{C}_{5}$ increased. The population structure was similar to January, in that relative abundance systematically decreased with stage between $\mathrm{N}_{3}$ and $\mathrm{C}_{4}$. Stage $\mathrm{N}_{3}$ was abundant all across the bank. High abundance centers of $\mathrm{N}_{4}-\mathrm{N}_{6}$ were located in the northwest portion and on the Northeast Peak. The maximum abundances of $\mathrm{C}_{1}$ to $\mathrm{C}_{3}$ were slightly south of the Northeast Peak. Moderate numbers of $\mathrm{C}_{6}$ were located along the Northern Flank and the eastern portion of the bank.

In March, nauplii became more numerous all across the bank. Numbers of copepodids and adults increased, and the Southern Flank became a population center of copepodids, particularly the earlier stages $C_{1}$ to $C_{3}$. Older stages tended to be more abundant around the 
bank periphery and less so on the Crest.

Abundances of copepodids continued increasing in April, whereas naupliar abundance remained relatively constant. The resulting springtime age structure of $\mathrm{N}_{3}$ to $\mathrm{C}_{5}$ was much more even than in the winter months. The April distribution of $\mathrm{N}_{3}$ to $\mathrm{C}_{5}$ on the bank was nearly uniform, although for most stages the Crest contained slightly lower abundance than the surrounding areas. For the adult stage, the contrast in abundance between the Crest and bank periphery remained more pronounced.

In May, abundances of $\mathrm{N}_{3}$ to $\mathrm{C}_{3}$ declined, especially on the Crest. In contrast, the abundances of $\mathrm{C}_{4}$ and $\mathrm{C}_{5}$ increased slightly from April to May, maintaining their relatively uniform distribution over the bank. The overall abundance of adults remained nearly constant, with a decrease in abundance on the Crest compensated by modest increases along the bank periphery.

In June, abundances of nauplii increased again, indicating the initiation of a new generation. Abundances of copepodids dropped sharply on the bank, with particularly low abundances of $\mathrm{C}_{1}$ to $\mathrm{C}_{6}$ on the Crest. Along the bank periphery, $\mathrm{C}_{4}$ to $\mathrm{C}_{6}$ remained relatively numerous.

\subsection{Forward model}

The forward model is an off-line version ("Acadia") of a finite element hydrodynamic model developed at the Dartmouth Numerical Methods Laboratory (Lynch et al., 1996). The circulation model includes tidal forcing, wind, and density driven flows (Naimie et al., 1994). The domain of computation includes GB, the GOM, and Scotian Shelf. Horizontal grid spacing 
is as fine as $1 \mathrm{~km}$ in regions of steep topography. Archived bimonthly climatologies ${ }^{1}$ for JanuaryFebruary, March-April, and May-June were used as input for off-line transport calculations. These simulations were run from January 15 to June 15 , with observations of $C$. finmarchicus specified on a monthly basis (see section 2.3 below). The temporal resolution of the hydrodynamic climatology used to drive the transport model is thus coarser than that of the $C$. finmarchicus climatology. However, the bimonthly hydrodynamic climatology is demonstrably consistent with available observations (Naimie, 1996; Naimie et al., 2001) and represents basic features of the circulation system in the domain.

The forward model is written

$$
\begin{aligned}
& \frac{\partial C_{i}}{\partial t}+\mathbf{v} \cdot \nabla C_{i}-\frac{1}{H} \nabla \cdot\left(H K \nabla C_{i}\right) \\
& =\delta_{i-1} R-F_{i}+\left(F_{i-1}+\mu_{i} C_{i}\right)\left(1-\delta_{i-1}\right)
\end{aligned}
$$

Here $\mathrm{C}$ is the vertically averaged zooplankton concentration, $H$ the bottom depth, $\mathbf{v}$ the vertically-averaged velocity and $K$ the horizontal diffusivity from the bimonthly climatology. Prior to assimilation, the vertically integrated abundance data (Figure 3) were transformed into vertically averaged concentrations by dividing by the bottom depth. The modeled zooplankton concentrations were changed back to the vertically-integrated abundances for presentation, so as to be consistent with the data units of the observations. Subscript $i$ is the stage index, with 1 to 10 representing $\mathrm{N}_{3}$ to $\mathrm{C}_{6}$, respectively. $R$ includes the input sources and mortality of $\mathrm{N}_{3}$, with $\delta_{i-1}$ a function that is 1 at $\mathrm{i}=1$ and zero at other stages. $F_{i}$ and $\mu_{i}$ represent stage-specific molting flux and mortality, respectively. Sign conventions are such that molting flux is positive and

\footnotetext{
${ }^{1}$ See http://www-nml.dartmouth.edu/
} 
mortality is negative (Equation 1).

Molting fluxes at stages $\mathrm{N}_{3}-\mathrm{C}_{5}$ are computed according to

$$
F_{i}=\frac{C_{i}}{D_{i}}
$$

where the stage-specific duration $\mathrm{D}_{i}$ depends on both temperature and food availability. In a food abundant condition, the temperature-limited stage duration $D_{T}$ is described by the Belehradek equation

$$
\left(D_{T}\right)_{i}=a_{i}\left(T_{m}-\alpha\right)^{\beta}
$$

The parameters $a_{i}, \alpha$, and $\beta$ are specified according to Campbell et al. (2001); $T_{m}$ is the vertically-averaged bimonthly climatological temperature from Lynch et al. (1996).

The effect of food availability on the stage duration was estimated from the Ivlev function (e.g., Campbell et al., 2001). At $\mathrm{T}=8^{\circ} \mathrm{C}$, the food dependent stage duration $D_{C h l}$ is represented as

$$
\left(D_{C h l}\right)_{i}=\frac{1}{b_{i}\left(1-e^{\left(-0.0253 *\left(C h l_{C}+4.968\right)\right)}\right)}
$$

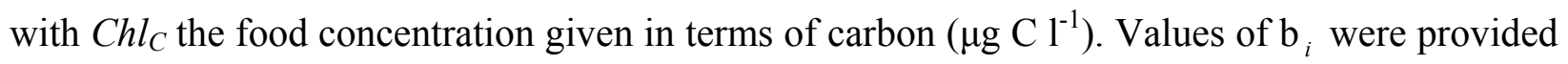
by Campbell (2003, personal communication), based on the data presented in Campbell et al. (2001). The food concentration was obtained from the climatological chlorophyll fields derived from the MARMAP observations during 1977-1987 (O'Reilly and Zetlin, 1996). Although the chlorophyll climatology is not contemporaneous with the $C$. finmarchicus climatology computed herein, we are not aware of any other regional climatology of in situ chlorophyll data that would be more suitable for the present application. The ratio of carbon to chlorophyll was set to $50 \mathrm{mg}$ C (mg Chl a) $)^{-1}$, consistent with previous studies (e.g., Hind et al., 2000; Hirche and 
Kwasniewski, 1997).

If we assume that food concentration has the same proportionate effect at all temperatures, the temperature and food dependent duration $\mathrm{D}_{i}$ is thus

$$
D_{i}=\left.\left(D_{T}\right)_{i}\right|_{T=T_{m}} * \frac{\left(D_{C h l}\right)_{i}}{\left.\left(D_{T}\right)_{i}\right|_{T=8}}
$$

We regard the estimation of the stage duration described above as a first-order approximation of true food-temperature dependency, ignoring complex details about food-temperature interaction.

\subsection{Inversion procedure}

The inverse problem is formulated as an optimization problem, in which a cost function measuring the model-data misfit is minimized, while being constrained by the model dynamics (e.g., Tziperman and Thacker, 1989). The adjoint technique can efficiently compute the gradient of the cost function with respect to model parameters and other inputs by integrating the dynamic model forward and its adjoint model backward (e.g., Li and Wunsch, 2004) in time. A gradientbased algorithm is then used to find the minimum of the cost function in an iterative procedure.

The adjoint method is well documented in literature (e.g., Wunsch, 1996). This method has been widely applied to optimal control problems in engineering (e.g., Hasdorff, 1976). In meteorology and oceanography, the use of adjoint techniques can be dated back to the 1980s, for both sensitivity analysis (e.g., Hall, 1986) and data assimilation (e.g., Thacker and Long, 1988). The innovation of the Adjoint Model Compiler ${ }^{2}$, which produces the adjoint model in a semiautomatic way, helps overcome the burden of writing the adjoint code (Giering and Kaminski, 1998). The adjoint method has been successfully applied in ocean state estimation (e.g., Moore, 1991; Stammer et al., 2002) and the study of transient tracers (Li and Wunsch, 2003). Lawson et

\footnotetext{
${ }^{2} \mathrm{http}: / /$ www.autodiff.com/tamc/
} 
al. (1995; 1996) used this method in simple ecosystem models for biological parameter estimation; also see Hofmann and Friedrichs (2001). This method has also been applied in the GB/GOM region to investigate the mechanisms controlling the distributions of adult Pseudocalanus spp. (McGillicuddy et al., 1998), and P. moultoni / P. newmani (McGillicuddy and Bucklin 2002). Note that the present formulation of the inverse problem for $C$. finmarchicus includes more detailed population dynamics (multiple life stages, temperature- and fooddependent stage duration, density dependent mortality) than these prior studies of Pseudocalanus.

We seek to minimize the misfit between simulated and observed concentrations of $C$. finmarchicus, subject to the constraint that the forward model (Equation 1) is strictly obeyed. The model-data misfit, or cost function $J$, is defined to be

$$
J=\frac{1}{N_{\text {mon }}} \sum_{k}^{N_{\text {mon }}} \frac{1}{N_{\text {stage }}} \sum_{j}^{N_{\text {stage }}} \frac{1}{N_{\text {obs }}} \sum_{i}^{N_{\text {obs }}}\left(C_{m}-C_{\text {obs }}\right)^{2}
$$

where $C_{m}$ and $C_{o b s}$ are modeled and observed $C$. finmarchicus concentrations, $N_{\text {mon }}$ the number of months in the integration period, $N_{\text {stage }}$ the number of modeled stages, and $N_{o b s}$ the number of observations at each stage in each month. In this application, we have chosen to assimilate the objectively analyzed maps of $C$. finmarchicus (Figure 3) rather than the raw observations themselves. This allows us to specify an "observation" at every node on the bank, so $N_{o b s}$ becomes the number of nodes (3688) in the colored areas of Figure 3. This approach imposes a spatial regularization on the inversion, set by the correlation length scales specified in the objective analysis. 
The cost function is minimized in an iterative procedure consisting of the following steps: (1) starting with initial estimate of the control parameters (the unknowns in the C. finmarchicus population dynamics model), the forward model is integrated to evaluate the cost function; (2) the adjoint model is integrated backward in time to compute the gradient of the cost function with respect to the control parameters; and (3) improved estimates of the control parameters are computed. The control parameters for this problem are the monthly varying source/sink $R$ (input source + mortality) of $N_{3}$, mortality $\mu_{i}$ at stages $N_{4}-C_{6}$ over the whole model domain, and the initial off-bank fields on January 15 where observations were not present (model domain is larger than the area plotted in Figure 3). All control variables were allowed to vary independently at corresponding model nodes. The first-guess values of all control variables were set to zero.

Within the iterative framework, the control parameters are updated with a quasi-Newton algorithm for solving large nonlinear optimization with simple bounds (Byrd et al., 1995; Zhu et al., 1994). Bound constraints on control variables keep the inferred parameters within meaningful limits. We impose upper bounds of zero for mortality rates (recall mortality is negative given the sign convention in Equation 1) and lower bounds of zero for initial zooplankton concentrations. In order to speed up convergence, the control variables were preconditioned with $u=u_{i} / a_{i}$, where $u_{i}$ are the control variables and $a_{i}$ are the corresponding preconditioners. The preconditioning transformation needs not define variables with any simple physical interpretation, but was used to reduce the conditioning number (the ratio of the largest to the smallest eigenvalues) of the Hessian matrix (e.g., Tziperman and Thacker, 1989). Preconditioners were $20,5.6,2.1,0.8,0.1,0.2,0.3,1,7,6\left(\#^{-3}\right)$ for the initial concentrations of $N_{3}$ to $C_{6}$ in the GOM, respectively. The values of preconditioners approximated the mean concentrations of $C$. finmarchicus observed in the southern GOM in January broad-scale surveys. 
Concentrations in the northern GOM (not observed in the broad-scale surveys) can be quite different (Durbin et al., 2003). However, we lack sufficient data to incorporate spatial varying preconditioners over the entire GOM. In the Slope Water, preconditioners were set to $0.01,0.01$, $0.01,0.01,0.01,0.01,0.01,0.01,0.1,0.1\left(\# \mathrm{~m}^{-3}\right)$ for $\mathrm{N}_{3}$ to $\mathrm{C}_{6}$, respectively. These values reflect the low abundance of $C$. finmarchicus in Slope Waters during January (Miller et al., 1991). Moreover, we force concentrations in Slope Water to zero in the forward model, based on the fact that the organism generally resides in strata that are too deep (ca. $500 \mathrm{~m}$ ) to be readily transported on-bank (Miller et al., 1991). This forcing in Slope Waters is applied by the addition of an extra term on the right hand side of Equation 1, independent from the estimated mortality. Preconditioners were $10^{-5}\left(\# \mathrm{~m}^{-3} \mathrm{~s}^{-1}\right)$ for $\mathrm{R}$ and $10^{-7} \mathrm{~s}^{-1}$ for all mortality rates $\mu_{i}$ in the first few iterations, and $10^{-3}\left(\# \mathrm{~m}^{-3} \mathrm{~s}^{-1}\right)$ for $\mathrm{R}$ and $10^{-5} \mathrm{~s}^{-1}$ for $\mu_{i}$ afterward. Resetting preconditioners of $\mathrm{R}$ and $\mu_{i}$ reflects a strategy to recover the initial conditions first, followed by the rate parameters. Iteration was terminated when the cost function no longer dropped significantly, even by resetting the preconditioners.

\section{Results}

\subsection{Constrained model performance}

Model performance was dramatically improved by the optimal estimates of initial fields in January, space-time varying sources/sinks of $\mathrm{N}_{3}$ and mortality rates at stages $\mathrm{N}_{4}$ to $\mathrm{C}_{6}$. After the inversion, model-data misfit was reduced by about 93\%, approximately an order of magnitude less than that resulting from the initial values of the control variables (all zero). The inversion successfully reproduced the most salient features of the observations both in terms of 
bank-wide averages (Figure 4b) and spatial distributions (Figure 5). The initial model conditions on GB were identical to the observations, with relatively high abundances of $\mathrm{N}_{3}$ and $\mathrm{N}_{4}$ in the northern portion of the bank, relatively high abundance of $\mathrm{N}_{5}$ on the Northeast Peak, low abundances of $\mathrm{C}_{1}$ to $\mathrm{C}_{4}$ on the entire bank, and moderate abundances of $\mathrm{C}_{5}$ and $\mathrm{C}_{6}$ along the bank's northern periphery. In February, naupliar and younger copepodid stages increased dramatically, whereas $\mathrm{C}_{5}$ and $\mathrm{C}_{6}$ showed modest decreases and increases, respectively. During March-April, the population of C. finmarchicus reached its peak abundance. In May, abundances of $\mathrm{N}_{3}$ to $\mathrm{C}_{3}$ declined, while abundances of $\mathrm{C}_{4}$ to $\mathrm{C}_{6}$ continued increasing. Naupliar and $\mathrm{C}_{1}$ abundances increased again in June, while $\mathrm{C}_{2}$ to $\mathrm{C}_{6}$ decreased, especially on the Crest.

\subsection{Inferred initial conditions}

The inversion successfully produced initial conditions in the off-bank regions in January (Figure 6). Low concentrations of all stages are present in the Slope Water, as the preconditioners express prior knowledge of the animal's low abundance in that area during January. In contrast, information from the observations on GB propagated upstream into the GOM, with moderate abundances of $\mathrm{C}_{4}, \mathrm{C}_{5}$ and $\mathrm{C}_{6}$ inferred over the deep basins of the Gulf. These results are generally in agreement with the 1977-1987 regional climatology for $\mathrm{C}_{3}$ to $\mathrm{C}_{6}$ described by Meise and O'Reilly (1996). Significant abundance of early naupliar stages (especially $\mathrm{N}_{3}$ ) is also inferred. Observations in the southern GOM reported by Durbin et al. (1997) are consistent with these findings; however, there is a paucity of data to constrain early season abundance of younger stages in the northern GOM. Nevertheless, the inferred initial conditions suggest emergence from diapause and the start of reproduction prior to January, a conclusion made also by Durbin et al. (1997). 


\subsection{Inferred source/sink of $N_{3}$}

Because $N_{3}$ is the youngest stage resolved in the model, its sources and sinks are aggregated into a single term $\left(\delta_{i-1} R\right.$ in Equation 1). Positive values constitute net addition of animals, whereas negative values constitute net removal. The source of $\mathrm{N}_{3}$ is the unknown molting from the unresolved stage $\mathrm{N}_{2}$, whereas sinks of $\mathrm{N}_{3}$ include both molting to $\mathrm{N}_{4}$ (computed from the $\mathrm{N}_{3}$ distribution and Equation 2 above) and the unknown mortality. Physical transport terms can act as both sources and sinks, depending on the spatial gradients of the organism and the specified velocity and diffusivity fields. The $\delta_{i-1} R$ term thus amalgamates an inferred source (molting from $\mathrm{N}_{2}$ ) and sink (mortality of $\mathrm{N}_{3}$ ) to achieve a solution that is consistent with observed distributions of $\mathrm{N}_{3}$ and the sources and sinks that are specified in the forward model (transport and molting to $\mathrm{N}_{4}$ ).

The sign of the inferred $\delta_{i-1} R$ term is generally positive, owing to its predominate role as a source of $\mathrm{N}_{3}$ copepodids (Figure 7). In January-February, the strongest positive values appear on the Northeast Peak and the northwest portion of the bank, although a net source is evident all along the northern edge of the bank. Positive values persist on the Northeast Peak and along the northern edge through March-April. Mortality is prevalent on the Southern Flank inshore of the $200 \mathrm{~m}$ isobath from January-February to February-March. Net sources and sinks are weak throughout in April-May, and then become strong again along the bank periphery in May-June. Note that a strong source persists in the Northeast Channel throughout the simulation in order to maintain the high abundances of $\mathrm{N}_{3}$ observed there.

Another salient feature of the inferred $\delta_{i-1} R$ distribution is the presence of bands of alternating small-scale sources and sinks. These tend to occur mostly along pathways of high transport (e.g. the Northern and Southern Flanks), where the advection terms are of the same 
order as the biological terms (see below). In these areas, we tend to interpret the spatial average of $\delta_{i-1} R$ (which is near zero along the transport pathway) rather than its detailed spatial distribution, as these structures may be sensitive to mesh resolution. There is an additional factor to consider pertaining to the strong sources and sinks at the offshore periphery of the Southern Flank. They occur along the interface between on-bank areas constrained by the GLOBEC data and the Slope Waters south of the bank in which the copepod concentrations are forced to zero. These features are likely to be an artifact of the forcing applied to the Slope Water side of that boundary, and therefore we are not inclined to interpret results of the inversion in that area.

\subsection{Computed molting fluxes}

The computed molting fluxes quantify the rate at which individuals develop from one stage to the next. Strong seasonal variability in molting flux is evident amongst the various stages (Figure 8). During January-February, the nauplii developed mostly on GB (except on the southwestern portion) and the Great South Channel. Development of copepodids on the bank was modest, owing to their low abundance during that period. During February-March, molting fluxes of nauplii were strong on GB and its adjacent off-bank regions; in the deep basins of the GOM, molting fluxes of the youngest naupliar stages were most prominent. Molting fluxes of both nauplii and younger stage copepodids increased substantially during March-April, with the overall amplitude decreasing with stage in accordance with the age structure of the population. Molting fluxes in the GOM were highest in the youngest naupliar stages, and systematically decreased with stage. In April-May, naupliar molting fluxes increased in the GOM, but decreased on GB. In contrast, copepodid molting fluxes increased in both the GOM and GB. During May-June, molting fluxes of stages $\mathrm{N}_{3}-\mathrm{N}_{5}$ remained large on the bank, while those of 
$\mathrm{N}_{6}$ to $\mathrm{C}_{4}$ dropped sharply. Molting fluxes in the GOM decreased for all stages except for $\mathrm{C}_{4}$ and $\mathrm{C}_{5}$ copepodids, which increased in May-June.

It is interesting that significant molting fluxes of copepodids west of the Great South Channel did not appear until March-April in our model. Smith and Lane (1988) found that $C$. finmarchicus copepodids did not begin to increase in the New York Bight until March. The increase occurred first to the east, suggesting an advective input from upstream, consistent with the present model.

\subsection{Inferred mortality}

The inferred mortality distributions reveal significant structure in time and space (Figure 9). In general, highest mortalities occurred on the bank and in the adjacent areas of the Great South Channel, the Northeast Channel, and southern Georges Basin. Two major episodes of mortality affected the nauplii and early copepodids $\left(\mathrm{C}_{1}\right.$ and $\left.\mathrm{C}_{2}\right)$, the first at the beginning of the growing season (January-February and February-March) and the second during May-June. Mortality of these stages was relatively modest during the intervening period (March-April and April-May). Copepodid stages $\mathrm{C}_{3}$ and $\mathrm{C}_{4}$ suffered comparatively little mortality throughout the simulated time period, except for a few hotspots in the southern Great South Channel in AprilMay, and the eastern side of the Crest during May-June. Mortality of the oldest stages $\mathrm{C}_{5}$ and $\mathrm{C}_{6}$ was very low at the beginning of the growing season and generally increased over time.

Spatial coherence in mortality patterns makes it possible to compute meaningful bankwide $^{3}$ averages (Figure 10). In January-February, the naupliar and younger copepodid stages bore the brunt of the losses: mortality peaked at copepodid $\mathrm{C}_{1}$, and decreased monotonically to 
the adult stage. In February-March, mortality of the younger naupliar stages decreased and oldest copepodid stages began to increase, resulting in a bimodal stage distribution of mortality. This bimodal characteristic persisted in March-April, albeit with lower mortality in the naupliar and early copepodid stages. The bimodality was accentuated in the last two bimonthly periods due to increasing mortality in the oldest copepodid stages and the sharply increasing mortality of $\mathrm{N}_{5}{ }^{-}$ $\mathrm{C}_{2}$ in May-June. Interestingly, this bimodal characteristic is robust in the spatially and temporally averaged mortality (Figure 11).

\subsection{Computed divergence of advective fluxes}

The influence of advection varied considerably in time and space, with distinct patterns amongst the various life stages evident in the advective flux divergence ${ }^{4}$ (Figure 12). Positive (negative) values indicate an increase (decrease) in abundance by the divergence of the advective fluxes. In January-February, the most pronounced signals occurred in the youngest stages, in association with southwestward transport of the abundant nauplii present on the NEP. Advection along the Southern Flank was illuminated by alternating small-scale regions of positive and negative values, which average out to near zero along the transport pathway. The overall magnitude of the advective terms decreased systematically with stage in January-February, such that there are no discernible patterns in the copepodid stages.

From February-March into March-April, southwestward transport intensified and reached farther down the Southern Flank. During this time the advective influence also spread into the

\footnotetext{
${ }^{3}$ For the purposes of these and all subsequent bank-wide averages, Georges Bank is defined to be the area inside the $200 \mathrm{~m}$ isobath, bounded by $68.8^{\circ} \mathrm{W}$ meridian to the west.

${ }^{4}$ In this context the term divergence is used to describe the mathematical operator $\frac{\partial}{\partial x}+\frac{\partial}{\partial y}$. When operating on advective or diffusive fluxes, the result can be either positive (convergence) or negative (divergence in the more specific sense).
} 
older stages as they increase in abundance. Note that during this time an advective source of nauplii and early stage copepodids appeared west of the Great South Channel leading into the southern New England shelf, confirming that westward transport lies at the heart of the apparent consistency of the solution with the findings of the Smith and Lane (1988) described above.

In April-May, the magnitude of the advective terms decreased in the naupliar and first copepodid stages as they temporarily declined in abundance. In contrast, advection of the copepodid stages $\mathrm{C}_{2}-\mathrm{C}_{5}$ intensified, with the transport pathway beginning to reach all the way around the bank. The around-bank transport became even more prominent in May-June, particularly in the younger naupliar stages.

\subsection{Computed divergence of diffusive fluxes}

The divergence of the diffusive fluxes (Figure 13) was dominated by small-scale structures, transporting these animals down-gradient. The most prominent organized feature in the fields is a banded structure along the southern flank of GB comprised of strips of negative and positive values at the edge of the shelf break. These are associated with a net off-bank diffusive transport operating on the concentration gradient maintained by the high abundance of C. finmarchicus on the bank and its absence in the adjacent Slope Waters ${ }^{5}$. In general, the net effect of diffusion in the interior of GB and in the GOM is rather modest, tending to smooth out peaks in the distribution of the organism.

\subsection{Bank-wide term averages}

The temporally and spatially averaged values of those physical and biological controls on GB provide insight into their relative effect on C. finmarchicus population dynamics (Figure 14).

\footnotetext{
${ }^{5}$ Recall that the model solution is forced to zero concentration in Slope Waters south of GB.
} 
On average, biological reaction terms govern the annual population cycle on GB. The space-time averaged convergences of advective and diffusive fluxes over GB are small relative to net molting fluxes $\left(F_{i-1}-F_{i}\right)$ and mortality. The standard deviations of physical transports, however, are large and vary with stage and time. Casting the term balances in terms of magnitude (Figure 15), physical transports are clearly of the same order as the biological sources and sinks. Thus, physical transports are locally important, even though inputs and outputs tend to counterbalance each other when spatially averaged over the bank.

Although their net effect is small, the bank-wide averages of the transport terms do exhibit some clear trends. For example, diffusive transport off the bank constitutes a net loss of C. finmarchicus for all stages at all times. The term maps (Figure 13) suggest this results primarily from diffusive flux across the shelf break on the Southern Flank (see above). Generally speaking, advection provides a net source of naupliar stages $\mathrm{N}_{4}$ and $\mathrm{N}_{5}$ early in the growing season. In contrast, advection tends to be a net sink for the older copepodids, especially in April-May and May-June. This latter effect tends to be associated with westward transport off the bank from the Southern Flank into the Great South Channel (Figure 12).

The population increase of nauplii and copepodids on GB from January-February through March-April results mainly from biological processes. For each life stage, the input molting flux $\left(F_{i-1}\right)$ is greater than the output molting flux $\left(F_{i}\right)$. More animals are entering into the population than are leaving it. However, mortality strongly limits the rate of population increase. The net change in abundance thus results from a relatively modest difference between net molting fluxes and mortalities of comparable magnitude.

The April-May period is characterized by a significant decrease in naupliar abundance. These results suggest this decline is primarily controlled by a decrease in net molting flux rather 
than an increase in mortality. Indeed, naupliar mortality actually tends to decrease during this period. Interestingly, the $\mathrm{N}_{4}$ and $\mathrm{N}_{5}$ net molting fluxes become negative in April-May, indicating that input of new recruits is not sufficient to keep up with the maturation rate of these stages. That trend reverses in May-June, with $\mathrm{N}_{4}$ and $\mathrm{N}_{5}$ net molting fluxes regaining positive values.

The May-June rebound of the naupliar stages is not mimicked in the copepodid stages, which all tend to decrease during that period. For adults, the decline is brought about by an increase in mortality that outpaces an increase in net molting flux. In contrast, the decline of $\mathrm{C}_{5}$ occurs in association with a decrease in net molting flux and mortality that is only slightly lower than its value from the prior period. The most precipitous decline in copepodids occurs in the younger stages, with $\mathrm{C}_{3}$ and $\mathrm{C}_{4}$ experiencing negative net molting fluxes during this period. Net molting fluxes of $\mathrm{C}_{1}$ and $\mathrm{C}_{2}$ remain positive, so the late season decline in their abundance is brought about primarily by mortality in excess of net molting flux.

\section{Discussion}

\subsection{Is the vernal population increase under biological control?}

What controls the springtime profusion of $C$. finmarchicus on GB? The results presented herein are suggestive of two mechanisms. First, the inverse procedure generated off-bank initial conditions that contained significant numbers of both nauplii and copepodid stages in the deep basins of the GOM upstream of GB (Figure 6). The inferred initial conditions are consistent with available observations of the later stage copepodids (Meise and O'Reilly, 1996), and indicate that advective supply contributes to the vernal population increase on GB. Indeed, earlier modeling studies have focused on the importance of this pathway (Lynch et al., 1998; 
Miller et al., 1998; Hannah et al., 1998). Despite this apparent advective connection, bank-wide average term balances indicate the predominance of biological processes over physical transport in controlling temporal changes in abundance (Figure 14).

In order to quantify the impact of the upstream sources, an additional inversion was undertaken in which all off-bank sources were eliminated. Specifically, all off-bank concentrations were set to zero in the initial condition, and the off-bank sources of $\mathrm{N}_{3}(R$ in Equation 1) were assumed to be null throughout the duration of the simulation. The resulting abundance fields (not shown) are quite similar to the baseline case (Figure 5), although the fit to the observations (as reflected in the final value of the cost function) is not quite as good as the solution in which the off-bank sources are active.

How was the inverse model able to match the observations in the absence of upstream sources? One way is to increase the inferred local source of $\mathrm{N}_{3}$ on Georges Bank. Indeed, the inversion procedure did increase the net source of $\mathrm{N}_{3}\left(\delta_{i-1} R\right.$ in Equation 1; see Figure 7 for maps from the baseline inversion) by an average of $33 \%$ on the bank during the period from January to June. The other way to counterbalance elimination of advective transport of $C$. finmarchicus to Georges Bank in the second model is to decrease the inferred mortality rates (Figure 16). Surprisingly, the reduction in mortality required to compensate for the lack of upstream sources is indistinguishably small given the range of experimental determinations of mortality (see section 4.2 below).

That the sources of $\mathrm{N}_{3}$ and mortality fields inferred in the two cases are so similar indicates upstream sources do not control the springtime population increase (Figure 16). If upstream sources were critical, then fitting the data with the second model would have required a large increase (on the order of $100 \%$ or more) in the local source of $\mathrm{N}_{3}$ on Georges Bank, and/or 
unrealistically low values of mortality. Alternatively, the second model might not have been able to fit the data at all. The fact that the second model can match the observations with only modest adjustments to the two control parameters therefore suggests a secondary role for upstream sources during this time period.

It is important to note that this result does not completely refute the relevance of upstream sources to the springtime population increase. These calculations are based on initial conditions for GB in January that were undoubtedly influenced to some degree by upstream sources. However, it is not possible to quantify the impact of upstream sources on the initial conditions. What is clear from these experiments is that upstream sources need not be invoked to simulate the observed population increase from January to June.

\subsection{Mortality estimates}

C. finmarchicus is subject to predation from a variety of animals, including chaetognaths, ctenophores, omnivorous copepods, and fish (e.g., Davis, 1984b; Sullivan and Meise, 1996; Dalpapado et al., 2000; Sell et al., 2001). The range of mortalities inferred herein (0.01-0.2 $\left.\mathrm{d}^{-1}\right)$ generally falls within the envelope of observational estimates of predation ${ }^{6}$. Interestingly, some

of the highest inferred mortalities occur on the Crest, where the presence of voracious planktonic hydroids has been estimated to result in removal of $50-100 \%$ of the daily production of young copepods (Madin et al., 1996).

The general pattern of the inferred stage-specified mortality (Figure 11) is similar to estimates derived from a vertical life table analysis of the same data by Ohman et al. (2002). Both studies suggest relative maxima in mortality in the late naupliar / early copepodid stages

\footnotetext{
${ }^{6}$ Specific rates of predation on C. finmarchicus copepodids based on observed predator abundance and feeding rates are available at: http://userwww.sfsu.edu/ bioocean/research/gbpredation/gbpredation1.html.
} 
and the later copepodid stages ${ }^{7}$. However, the mortalities estimated herein are systematically lower than those reported by Ohman et al. by approximately $20-40 \%$.

There are several possible reasons for these differences. To begin with, the vertical life table approach is not spatially explicit and therefore cannot account directly for the effects of advection (Aksnes and Ohman 1996; Aksnes et al., 1997). However, advection is an unlikely explanation for the differences in the mortality estimates for two reasons. First, analysis of the present model solution indicates the net impact of advection is small relative to molting and mortality terms in the population dynamics equation. Second, results presented in the preceding section illustrate how elimination of upstream sources can be compensated by a systematic decrease in mortality estimated by the inversion procedure. By analogy we speculate that the inclusion of upstream sources in the vertical life table approach would tend to increase the resulting mortality estimates, not decrease them.

Another difference between the present study and Ohman et al. (2002) is the temperature used to calculate stage duration in the Belehradek function (Equation 3). Our model uses the vertically averaged climatological temperature for each node, whereas Ohman et al. used the observed temperature at the mean depth occupied by each developmental stage at each station. To estimate the potential impact of vertical variations in temperature on the mean stage duration, we computed spatial maps of the vertically averaged stage duration based on the threedimensional climatological temperature and compared them with stage durations based on the vertically averaged temperature. Ratios of the two quantities on Georges Bank indicate minor differences, with the stage durations based on vertically averaged temperature slightly longer than those based on the three-dimensional climatology $(2.4 \pm 1.7 \%, 2.3 \pm 1.3 \%$, and $3.7 \pm 1.6 \%$, for

\footnotetext{
${ }^{7}$ Ohman et al. (2002) report a third peak in mortality between the egg and second naupliar stage which is not resolved by the present study because the youngest stage included herein is $\mathrm{N}_{3}$.
} 
January-February, March-April, and May-June, respectively). Thus the nonlinear relationship between stage duration and temperature gives rise to a potential bias, in that the decrease in stage duration in warmer surface waters overshadows the increased stage duration in cooler waters at depth. The longer stage duration predicted by the vertically averaged model translates linearly into decreased mortality estimates (Equations 1 and 2). However, the 2-4\% increases in mortality that would result from more realistic treatment of temperature variability would be barely perceptible in Figure 11. Therefore, it does not appear that temperature effects on stage duration are sufficient to explain the differences between our mortality estimates and those of Ohman et al. (2002). Nevertheless, this possibility cannot be discounted completely because the above comparison assumes uniform vertical distribution of the animal. Covariance of fluctuations in animal abundance and temperature could introduce additional bias.

A potentially more important difference between the two studies is the inclusion of food limitation. Evaluation of the ratio between stage durations based on temperature alone (Equation 3) with that derived from the combined effects of temperature and food (Equation 5) permits quantification of this effect (Table 1). Food limitation is significant in January-February, with stage durations on Georges Bank 55\% longer than they would be based on temperature alone. This finding is consistent with the somewhat lower RNA:DNA ratios observed in $C$. finmarchicus in January, which is indicative of food limitation (Wagner, 2000). The MarchApril phytoplankton bloom relaxes this effect, with the food-limited stage durations only $12 \%$ longer on average. Food limitation increases slightly in May-June, with the average stage duration being $15 \%$ longer than the temperature limited rate. Clearly the effect of food is significant, and the mean increase in stage duration (27\%) translates into commensurately lower estimates of mortality. Thus food limitation is a plausible explanation of the systematic 
differences between the present estimates of mortality and those of Ohman et al. (2002). Indeed, Ohman et al. discuss the potential impact of food limitation, noting that including this effect could potentially reduce their mortality estimates for feeding stages $\left(\mathrm{N}_{3}\right.$ to adult) by up to a factor of two.

\subsection{What causes the absence of late-stage copepodids on the Crest in June?}

The most salient characteristic of the late spring / early summer decline in copepodids is the near absence of older stages on the Crest (Figure 3). Term balances computed for the Crest region inside the $60 \mathrm{~m}$ isobath indicate that this is primarily a result of mortality, although the negative net molting fluxes in $\mathrm{C}_{3}$ and $\mathrm{C}_{4}$ also contribute to the decline of those stages (Table 2). Advective and diffusive terms are 1-2 orders of magnitude smaller. The modest influence of the transport terms is also consistent with seasonal modulation of hydrodynamic exchange between the Crest and surrounding waters (Hannah et al., 1998; McGillicuddy et al., 1998). Specifically, development of stratification in the summer accelerates an around-bank jet that tends to isolate the Crest from upstream supply of animals.

This apparent mortality of copepodids on the Crest is likely due to predation (see above), but there are other factors that could be important. C. finmarchicus is a boreal animal that prefers colder temperatures. Seasonal input of heat into the well-mixed waters of the Crest could make that environment unsuitable, whereas stratified waters of the bank periphery remain more hospitable because cooler waters are accessible at depth. Satellite imagery indicates sea surface temperatures on the crest reach $10-12^{\circ} \mathrm{C}$ in late spring / early summer (Bisagni et al. 2001). However, these temperatures do not cause deleterious effects on $C$. finmarchicus reared in the laboratory (Campbell et al. 2001). Nevertheless, it is possible that more subtle effects of increasing temperatures might adversely affect natural populations on the Crest, since this is 
close to the observed upper limit for field populations of C. finmarchicus in other parts of its range (Bonnet et al., 2005).

\subsection{Caveats}

There are a number of caveats that must be considered in the interpretation of these results. To begin with, it is not possible to demonstrate a priori that the assimilation procedure results in a global minimum of the cost function. The existence of local minima can be investigated by starting from different initial guesses of the control variables, as well as restarting the iterative procedure with perturbations to the control variables. Both of these approaches were pursued, and convergence to the reported solution appears to be stable. That the resulting solution closely resembles the observations (c.f. Figures 3-5) further attests to satisfactory solution of the minimization problem.

Several aspects of the basic formulation of the inverse problem are also worthy of note. First of all, the physical transport fields are specified with certainty. If the observed changes in abundance are incompatible with the prescribed circulation, the inversion technique will adjust the control variables (off-bank initial conditions, sources/sinks of $\mathrm{N}_{3}$, and mortality fields) to make up for those discrepancies. In this sense, it is possible for deficiencies in the circulation model to lead to anomalous biological inference. However, the most salient characteristics of the solutions presented herein are associated with robust features of the circulation on Georges Bank that are well documented in the literature (Naimie, 1996; Naimie et al., 2002). Nevertheless, the potential for nonlinear impacts of time-dependent flows (such as storm events) on the mean behavior of the system remains to be investigated. In this context, it would be beneficial to investigate the sensitivity of the results to the details of the hydrodynamic fields by performing biological inversions on ensembles of perturbations to the climatology that are all equally valid 
with respect to observations.

This is not to say that the vertically averaged model used herein is completely sufficient, especially in stratified conditions. Moreover, C. finmarchicus is capable of controlling its vertical position in the water column by swimming, and that behavior is not included in the present model. Indeed, earlier studies have illustrated the potential for layered organism distributions and vertical shear to have significant impact on the supply and retention of $C$. finmarchicus on Georges Bank. For example, the model of Lynch et al. (1998) showed how transport of copepodids from the deep basins of the Gulf of Maine to Georges Bank is favored by upward swimming of copepodids into the surface Ekman layer, where wind-driven surface currents provide a more direct transport pathway than the more circuitous flows at depth. The fact that this structure is not fully represented in the present model would tend to diminish the importance of advective supply of $C$. finmarchicus to the bank, and is therefore an important caveat in the present assessment of its importance relative to local biological processes. On the other hand, surface-intensified transport could also play a role in the export of $C$. finmarchicus off the bank. If so, then the vertically-averaged model could be too retentive, reducing the need for local sources to maintain the population. It remains to be seen whether vertical structure has more impact on supply or removal processes, and the degree to which these might compensate for each other in a vertically averaged model. Clearly, the inclusion of vertical dimension is an important avenue for future study.

\section{Conclusions}

The fundamental question posed in an inverse modeling approach is whether or not a set of data fit a particular model. In the present case, the answer is yes. Observations of the climatological distribution of $C$. finmarchicus were assimilated into a physical-biological model 
based on the climatological circulation. The population dynamics model specified temperatureand food-dependent stage duration, and the control parameters were off-bank initial conditions, a source term for the youngest stage in the model $\left(\mathrm{N}_{3}\right)$, and a seasonally varying stage-specific mortality field. This model fits the data insofar as the resulting inverse solutions capture the essential features of the observed distributions with values of the control parameters that are not unrealistic.

A more stringent test of the model would be provided by direct measurements of the control parameters. In principle it would be possible to alleviate the need to invert for off-bank initial conditions and sources of $\mathrm{N}_{3}$ by expanding the geographic coverage of the measurements and sampling the distributions of eggs and the first two naupliar stages. Such observations would permit a more complete model of the life cycle, spanning egg through adult stages and including reproduction. However, the issue of mortality remains much more problematic. $C$. finmarchicus is subject to predation by a wide variety of organisms, each with their own unique distribution, abundance, and feeding characteristics. Observational specification of space-time fluctuations in the aggregate impact of all predators on the target species is clearly not practical. Perhaps the most tractable way forward is to undertake comprehensive predation studies in a few key locations, and then invert for spatial variations in the rates that are constrained by such process studies.

Diagnosis of the inverse solutions provides some insight into the mechanisms controlling the mean January-June dynamics of $C$. finmarchicus on Georges Bank. That the inversion for initial conditions reached upstream and deposited animals in the deep basins of the Gulf of Maine implies connectivity between these regions on seasonal time scales. However, the sensitivity experiment in which upstream sources were set to zero showed that the model could 
still fit the data with only modest reductions in the inferred mortality and a minor increase in the local source of $\mathrm{N}_{3}$. Thus, advective delivery of animals from upstream does not appear to be a major contributor to the vernal population increase in this model. In other words, the initial conditions prescribed in January provide a sufficient seed population. Of course, the initial conditions themselves were influenced to some degree by upstream sources. Clearly the broader question of self-sustenance of $C$. finmarchicus on Georges Bank begs for a study of the entire annual cycle. Observations from the MARMAP (Sherman et al., 1996) and ECOMON (Link and Brodziak, 2002) programs would be quite useful for such purposes. In any case, the present results indicate the GLOBEC broad-scale surveys resolve a clear signal in the mean seasonal cycle of C. finmarchicus population dynamics that is not severely compromised by advective influences.

An important next step is to investigate interannual variability. Combination of climatological physics with climatological biology has illuminated some of the controls on the January-June monthly mean distribution of C. finmarchicus for 1995-1999. However, both the physical environment and the distribution of $C$. finmarchicus are prone to significant departures from climatology (Mountain and Taylor, 1998; Sherman et al., 1998; Greene and Pershing, 2000; Conversi et al., 2001; Durbin and Casas, this volume). There are several opportunities to explore interannual variability in this context. For example, the present results could be compared to an analogous inversion of the MARMAP years (1977-1987) to investigate changes in the mean state of the system between these two epochs. Another promising avenue would be to compare physical-biological hindcasts of specific years based on detailed three-dimensional hydrodynamic simulations being constructed for the GLOBEC era (Chen et al. 2003). Lastly, the significance of basin-scale processes in governing both the mean state and interannual 
variability in this region remains to be investigated. Basin-scale models of $C$. finmarchicus population dynamics are emerging (Speirs et al., 2005), and physical-biological interactions at these large scales (e.g. Heath et al., 2004) are a key topic for further research. 
Acknowledgments: This work was supported by the US GLOBEC Georges Bank program: Integration and Synthesis of Georges Bank Broad-Scale Survey Results, sponsored by NSF (OCE-0233800) and NOAA (NA17RJ1223). We are grateful for two anonymous reviews that led to substantial improvement over the original manuscript. We thank Maria Casas for providing us access to the zooplankton data base. Valery Kosnyrev, Olga Kosnyreva, Larry Anderson, and Charlie Stock helped with the visualization of the model outputs, and Sue Stasiowski assisted with manuscript preparation. Special thanks go to Cabell Davis for informative discussions. This is US GLOBEC contribution 282. 


\section{References}

Aksnes, D.L., Miller, C.B., Ohman, M.D., Wood, S.N., 1997. Estimation techniques used in studies of copepod population dynamics - a review of underlying assumptions. Sarsia, 82, 279-296.

Beardsley, R.C., Butman, B., Geyer, W.R., Smith, P., 1997. Physical oceanography of The Gulf of Maine: an update. Proceedings of the Gulf of Maine Ecosystem Dynamics Scientific Symposium and Workshop. Regional Association for Research in the Gulf of Maine, Hanover, NH, pp. 39-52.

Bigelow, H.B., 1927. Physical oceanography of the Gulf of Maine. Bulletin-U.S. Bureau of Fisheries, 40, 511-1027.

Bisagni, J.J., Seeman, K.W., Mavor, T.P., 2001. High-resolution satellite-derived sea-surface temperature variability over the Gulf of Maine and Georges Bank region, 1993-1996. Deep-Sea Research II, 48, 71-94.

Bonnet, D., Richardson, A., Harris, R., Hirst, A., Beaugrand, G., Edwards, M., Ceballos, S., Diekman, R., Lopez-Urrutia, A., Valdes, L., Carlotti, F., Molinero, J.C., Weikert, H., Greve, W., Lucic, D., Albaina, A., Yahia, N.D., Umani, S.F., Miranda, A., dos Santos, A., Cook, K., Robinson, S., Fernandez de Puelles, M.L, 2005. An overview of Calanus helgolandicus ecology in European waters. Progress in Oceanography. 65, 1-53.

Butman, B., Loder, J.W., Beardsley, R.C., 1987. The seasonal mean circulation: observation and theory. In: Backus, R. H., Bourne, D.W., (Eds.), Georges Bank, MIT Press, Cambridge, MA, pp. 125-138.

Byrd, R.H., Lu, P., Nocedal, J., 1995. A limited memory algorithm for bound constrained optimization. SIAM Journal on Scientific and Statistical Computing, 16, 1190-1208.

Campbell, R.G., Wagner, M.M., Teegarden, G.J., Boudreau, C.A., Durbin, E.G., 2001. Growth and development rates of the copepod Calanus finmarchicus reared in the laboratory. Mar. Ecol. Prog. Ser., 221, 161-183.

Carlotti, F., 1996. A realistic physical-biological model for Calanus finmarchicus in the North Atlantic. A conceptual approach. Ophelia, 44, 47-58.

Chen, C.H. Liu, Beardsley, R.C., 2003. An unstructured, finite-volume, three-dimensional, primitive equation ocean model: application to coastal ocean and estuaries. Journal of Atmospheric and Oceanic Technology, 20, 159-186.

Conversi, A., Piontkovski, S., Hameed, S., 2001. Seasonal and interannual dynamics of Calanus finmarchicus in the Gulf of Maine (Northeastern US shelf) with reference to the North Atlantic Oscillation, Deep-Sea Res., 48, 519-530.

Dalpadado, P., Ellertsen, B., Melle, W., Dommasnes, A., 2000. Food and feeding conditions of Norwegian spring-spawning herring (Clupea harengus) through its feeding migrations. ICES Journal of Marine Science, 57, 843-857.

Davis, C.S., 1984. Interaction of a copepod population with the mean circulation on Georges Bank. Journal of Marine Research, 42, 573-590.

Davis, C.S., 1984. Predatory control of copepod seasonal cycles on Georges Bank. Marine Biology, 82, 31-40.

Davis, C.S., 1987. Zooplankton life cycles. In: Backus, R. H., and D. W. Bourne (Eds.), Georges Bank. MIT Press, Cambridge, MA, pp. 256-267. 
Davis, C.S., Gallager, S.M., Solow, A.R., 1992a. Microaggregations of oceanic plankton observed by towed video microscopy. Science, 257, 230-232.

Davis, C.S., Gallager, S.M., Marra, M., Stewart. W.K., 1996. Rapid visualization of plankton abundance and taxonomic composition using the Video Plankton Recorder. Deep Sea Res. II, 43, 1947-1970.

Durbin, E.G., Runge, J.A., Campbell, R.G., Garrahan, P.R., Casas, M.C., Plourde, S. 1997. Late fall-early winter recruitment of Calanus finmarchicus on Georges Bank. Marine Ecology Progress Series, 151, 103-114.

Durbin, E.G., Garrahan, P.R., Casas, M.C., 2000a. Depth distribution of Calanus finmarchicus nauplii on the Georges Bank during 1995 and 1996. ICES Journal of Marine Science, 57, 1686-1693.

Durbin, E.G., Garrahan, P.R., Casas, M.C., 2000b. Abundance and distribution of Calanus finmarchicus on the Georges Bank during 1995 and 1996. ICES Journal of Marine Science, 57, 1664-1685.

Durbin, E.G., Campbell, R.G., Casas, M.C., Ohman, M.D., Niehoff, B., Runge, J., Wagner, M., 2003. Interannual variation in phytoplankton blooms and zooplankton productivity and abundance in the Gulf of Maine during winter. Marine Ecology Progress Series, 254, 81-100.

Eiane, K., Aksnes, D.L., Ohman, M.D., Wood, S., Martinussen, M.B., 2002. Stagespecific mortality of Calanus spp. under different predation regimes, Limnol. Oceanogr., 47, 636-645.

Flagg, C.N., 1987. Hydrographic structure and variability. In: Backus, R.H., Bourne, D.W. (Eds.), Georges Bank. MIT Press, Cambridge, MA, pp. 108-124.

Gangopadhyay, A., Robinson, A.R., Haley, P.J., Leslie, W.G., Lozano, C.J., Bisagni, J.J., $\mathrm{Yu}, \mathrm{Z}$., 2003. Feature-oriented regional modeling and simulations in the Gulf of Maine and Georges Bank. Continental Shelf Research, 12, 317-353.

Gentleman, W.C., 2000. Factors controlling the seasonal abundance and distribution of Calanus finmarchicus in the Gulf of Maine/Georges Bank region. Ph.D. thesis, Thayer School of Engineering, Dartmouth College, Hanover, New Hampshire.

Giering, R., Kaminski, T., 1998. Recipes for adjoint code construction. ACM Trans. On Math. Software, 24, 437-474.

Greene, C.H., Wiebe, P.H., Pelkie, C., Benfield, M.C., 1998. Three-dimensional acoustic visualization of zooplankton patchiness. Deep-Sea Research Part II, 45, 1201-1217.

Greene, C.H., Pershing, A.J., 2000. The response of Calanus finmarchicus populations to climate variability in the Northwest Atlantic: Basin-scale forcing associated with the North Atlantic Oscillation. ICES J. Mar. Sci., 57, 1536-1544.

Hall, M.C., 1986. Application of adjoint sensitivity theory to an atmospheric general circulation model. J. Atmos. Sci., 43, 2644-2651.

Hannah, C.G., Naimie, C.E., Loder, J.W., Werner, F.E., 1998. Upper-ocean transport mechanisms from the Gulf of Maine to Georges Bank, with implications for Calanus supply. Cont. Shelf Res., 17, 1887-1911.

Hasdorff, L., 1976. Gradient optimization and nonlinear control. Krieger Pub. Co., Malabar, Florida, $280 \mathrm{pp}$.

Haury, L.R., McGowan, J.A., Wiebe, P.H., 1978. Patterns and processes in the timespace scales of plankton distributions. In: Steele J.H. (Ed.), Spatial patterns in plankton communities. Plenum Press, New York, pp. 277-327. 
Heath, M., Boyle, P.R., Gislason, A., Gurney, W., Hay, S.J., Head, E.J.H., Holmes, S., Ingvarsdottir, A., Jonasdottir, S.H., Lindque, P., Pollard, R.T., Rasmussen, J., Richards, K., Rcihardson, K., Smerdon, G., Speirs, D., 2004. Comparative ecology of overwintering Calanus finmarchicus in the northern North Atlantic, and implications for life cycle patterns. ICES Journal of Marine Science, 61, 698-708.

Hendry, R., He, I., 2002. Technical report on objective analysis (OA) project. WWW Page, http: // www.mar.dfompo.gc.ca / science / ocean / coastal_hydrodynamics / Oax / oax.ht $\mathrm{ml}$.

Hind, A., Gurney, W.S.C., Heath, M., Bryant, A.D., 2000. Overwintering strategies in Calanus finmarchicus. Mar. Ecol. Prog. Ser., 193, 95-107.

Hirche, H-J, 1996. Diapause in the marine copepod, Calanus finmarchicus - a review. Ophelia, 44, 129-143.

Hirche, H-J, Kwasniewski, S.,1997. Distribution, reproduction and development of Calanus species in the northeast water in relation to environmental conditions. Journal of Marine Systems, 10, 299-317.

Hofmann, E.E., Freidrichs, 2001. Biogeochemical data assimilation. In: Encycolpedia of Ocean Science, Steele, J.H., Turekian, K.K., Thorpe, S.A. (Eds). Academic Press, London, 2820-2833.

Johnson, C., Pringle, J., Chen, C., 2005. Transport and Retention of Dormant Copepods in the Gulf of Maine. Deep Sea Research II, submitted.

Lawson, L.M., Spitz, Y.H., Hofmann, E.E., 1995. A data assimilation technique applied to a predator-prey model. Bull. Math. Biol., 57, 593-617.

Lawson, L.M., Hofmann, E.E., Spitz, H.Y., 1996. Time series sampling and data assimilation in a simple marine ecosystem model. Deep-Sea Res. II, 43, 625-651.

Li, X., Wunsch, C., 2003. Constraining the North Atlantic Circulation with between $4.5^{\circ} \mathrm{S}$ and $39.5^{\circ} \mathrm{N}$ with Transient Tracer Observations. Journal of Geophysical Research, 108(C10), doi:10.1029/2002JC001765.

Li, X., Wunsch, C., 2004. An adjoint sensitivity study of chlorofluorocarbons in the North Atlantic. Journal of Geophysical Research, 109(C01), doi:10.1029/2003JC002014.

Link, J.S., Brodziak, J.K.T., editors, and Brodziak, J.K.T., Dow, D.D., Edwards, S.F., Fabrizio, M.C., Fogarty, M.J., Hart, D., Jossi, J.W., Kane, J., Lang, K.L., Legault, C.M., Link, J.S., MacLean, S.A., Mountain, D.G., Olson, J., Overholtz, W.J., Palka, D.L., Smith, T.D., contributors. 2002. Status of the Northeast U.S. Continental Shelf Ecosystem: a report of the Northeast Fisheries Science Center's Ecosystem Status Working Group. Northeast Fish. Sci. Cent. Ref. Doc. 02-11; 245 p. Available from: National Marine Fisheries Service, 166 Water St., Woods Hole, MA 02543-1026.

Lynch, D.R., IP, J.T.C., Naimie, C.E., Werner, F.E., 1996. Comprehensive coastal circulation model with application to the Gulf of Maine. Continental Shelf Research, $16,875-906$.

Lynch, D.R., Gentleman, W.C., McGillicuddy, D.J. Jr., Davis, C.S., 1998.

Biological/physical simulations of Calanus finmarchicus population dynamics in the Gulf of Maine. Mar. Ecol. Prog. Ser. 169, 189-210.

Madin, L.P., Bollens, S.M., Horgan, E.F., Butler, M., Runge, J., Sullivan B.K., MacPhee, G., Durbin, E., Durbin, A.G., Van Kueren, D., Plourde, S., Bucklin, A., Clarke, M.E.,1996. Voratious planktonic hydroids: unexpected predatory impact on a coastal marine ecosystem. Deep-Sea Research II, 43: 1823-1829. 
McGillicuddy, D.J. Jr., Lynch, D.R., Moore, A.M., Gentleman, W.C., Davis, C.S., Meise, C.J., 1998. An adjoint data assimilation approach to diagnosis of physical and biological controls on Pseudocalanus spp. in the Gulf of Maine-Georges Bank region. Fish. Oceanogr., 7, 205-218.

McGillicuddy, D.J. Jr., Lynch, D.R., Wiebe, P.H., Runge, J., Durbin, G., Gentleman, W.C. Davis, C.S., 2001. Evaluating the synopticity of the US GLOBEC Georges Bank broad-scale sampling pattern with observational system simulation experiments. Deep-Sea Res. II, 48, 589-608.

McGillicuddy, D.J. Jr., Bucklin, A., 2002. Intermingling of two Pseudocalanus species on Georges Bank. J. Mar. Res., 60, 583-604.

Meise, C.J., O'Reilly, J.E., 1996. Spatial and seasonal patterns in abundance and ageComposition of Calanus finmarchicus in the Gulf of Maine and on Georges Bank: 1977-1987. Deep-Sea Res., II, 43, 1505-1519.

Miller, C.B., Cowles, T.J., Wiebe, P.H., Copley, N.J., Grigg, H., 1991. Phenology in Calanus finmarchicus; hypotheses about control mechanisms. Mar. Ecol. Prog. Ser., 72, 79-91.

Miller, C.B., Lynch, D.R., Carlotti, F., Gentleman, W.C., Lewis, C.V.W., 1998. Coupling of an individual-based population dynamic model of Calanus finmarchicus to a circulation model for the Georges Bank region. Fish. Oceanogr., 7, 219-234.

Moore, A.M., 1991. Data assimilation in a quasi-geostrophic open-ocean model of the Gulf Stream region using the adjoint method. J. Phys. Oceanogr., 21, 398-427

Mountain, D.G., Taylor, M.H., 1998. Spatial coherence of interannual variability in water properties on the U.S. northeast shelf. Journal of Geophysical Research 103, C2, 30833092.

Naimie, C.E., Loder, J.W., Lynch, D.R., 1994. Seasonal variation of the threedimensional residual circulation on Georges Bank. Journal of Geophysical Research, 99, 15, 967-15,989.

Naimie, C.E., 1996. Georges Bank residual circulation during weak and strong stratification periods: Prognostic numerical model results. Journal of Geophysical Research, 101, 6469-6486.

Naimie, C.E., Limeburner, R., Hannah, C.G., Beardsley, R.C., 2001. On the geostrophic and seasonal patterns of the near-surface circulation on Georges Bank - from real and simulated drifters. Deep-Sea Research II, 48, 501-518.

Ohman, M.D., Runge, J.A., Durbin, E.G., Field, D.B., Niehoff, B., 2002. On birth and death in the sea. Hydrobiologia, 480, 55-68.

O'Reilly, J.E., Zetlin, C., 1996. Monograph on the seasonal, horizontal, and vertical distribution of phytoplankton chlorophyll a in the northeast U. S. continental shelf ecosystem. NOAA Technical Report, National Marine Fisheries Service.

Sell, A.F., Keuren, D.V., Madin, L.P., 2001. Predation by omnivorous copepods on early developmental stages of Calanus finmarchicus and Pseudocalanus spp. Limnol. Oceanogr., 46, 953-959.

Sherman, K., Grosslein, M., Mountain, D., Busch, D., O'Reilly, J., Theroux, R., 1996. The Northeast Shelf Ecosystem: Assessment, Sustainability, and Management. In: K.A.T.S. Sherman, (Ed), The northeast shelf ecosystem: an initial perspective. Blackwell Science, Oxford, pp. 103-126. 
Sherman, K., Solow, A., Jossi, J., Kane, J., 1998. Biodiversity and abundance of the zooplankton of the Northeast Shelf ecosystem. ICES J. Mar. Sci. 55, 730-738.

Smith S.L., Lane, P.V.C., 1988. Grazing of the spring diatom bloom in the New York Bight by the calanoid copepods Calanus finmarchicus, Metridia lucens and Centropages typicus. Cont. Shelf. Res., 8, 485ÂA-509.

Speirs, D.C., Gurney, W.S.C., Heath, M.R., Hornbelt, W., Wood, S.N., de Cuevas, B.A., 2005. Modleing the basin-scale demnography of Calanus finmarchicus in the N.E.Atlantic. Fisheries Oceanography, 14, 5, 333-358.

Stammer, D., Wunsch, C., Giering, R., Eckert, C., Heimbach, P., Marotzke, J., Adcroft, A., Hill, C.N., Marshall, J., 2002. The global ocean state during 1992-1997, estimated from ocean observations and a general circulation model. J. Geophys. Res., 107(C9), doi:10.1029/2001JC000888.

Sullivan, B.K., Meise, C., 1996. Invertebrate predators of zooplankton on Georges Bank, 1977-1987. Deep-Sea. Res. II, 43, 1503-1519.

Thacker, W.C., Long, R.B., 1988. Fitting dynamics to data. Journal of Geophysical Research, 93(C2), 1227-1240.

Tittensor, D.P., DeYoung, B., Tang, C.L., 2003. Modelling the distribution, sustainability and diapause emergence timing of the copepod Calanus finamarchicus in the Labrador Sea. Fisheries Oceanography, 12, 4-5, 299-316, doi:10.1046/J.13652419.2003.00266.x.

Tziperman, E., Thacker, W.C., 1989. An optimal-control/adjoint-equations approach to studying the oceanic general circulation. Journal of Physical Oceanography, 19, 14711485.

Wagner, M. 2000. Nucleic acids as indicators of growth rates and nutritional condition of the copepod Calanus finmarchicus (Copepoda: Calanoida). Ph.D. Thesis. University of Rhode Island, Kingston, RI. $124 \mathrm{pp}$.

Wiebe, P.H., Morton, A.W., Bradley, A.M., Backus, R.H., Craddock, J.E., Cowles, T.J., Barber,V.A., and Flierl G.R., 1985. New developments in the MOCNESS, an apparatus for sampling zooplankton and micronekton. Marine Biology, 87, 313-323.

Wiebe, P.H., Mountain, D.G., Stanton, T.K., Greene, C.H., Lough, G., Kaartvedt, S., Dawson, J., Copley, N., 1996. Acoustical study of the spatial distribution of plankton on Georges Bank and the relationship between volume backscattering strength and the taxonomic composition of the plankton. Deep-Sea Res. II, 43, 1971-2001.

Wunsch, C.,1996. The ocean circulation inverse problem. Cambridge University Press.

Zakardjian, B.A., Sheng, J., Runge, J.A., Thompson, K.R., Gratton, Y., McLaren, I.A., Plourde, S., 2003. Effects of temperature and circulation on the population dynamics of Calanus finmarchicus in the Gulf of St. Lawrence and Scotian Shelf: Study with a coupled three-dimensional hydrodynamic, stage-based life-history model. J. Geophys. Res., 108, C11, 8016.

Zhu, C., Byrd, R.H., Nocedal, J., 1994. L-BFGS-B: FORTRAN subroutines for large scale bound constrained optimization. Tech. Report, NAM-11, EECS Department, Northwestern University. 


\section{Figure Captions}

Figure 1: Station locations of the U.S. GLOBEC GB broad-scale surveys between 1995-1999. MOCNESS samples are available at stations denoted by the black dots, and pump samples are available at stations denoted by circles.

Figure 2: Schematic diagram of the forward model (top), list of the specified and inferred model inputs (middle), and space/time characteristics of the various components used in the inverse problem described herein (bottom).

Figure 3: Mean monthly distributions of vertically integrated Calanus finmarchicus $\mathrm{N}_{3}-\mathrm{C}_{6}$ $\left[\log _{10}\left(1+\# / \mathrm{m}^{2}\right)\right]$ observed between 1995-1999. Station locations are indicated by black dots, which consists of pump samples for $\mathrm{N}_{3}-\mathrm{C}_{1}$ (open circles in Figure 1) and MOCNESS samples for $\mathrm{C}_{2}-\mathrm{C}_{6}$ (black dots in Figure 1). Geographic coverage of the maps is confined to the area in which the expected error computed in the objective analysis is less than approximately 40 percent. Isobaths shown are 60,100 , and $200 \mathrm{~m}$.

Figure 4: Observed (upper panel) and simulated (lower panel) bank-wide averages of stagespecific abundance.

Figure 5: Modeled abundances of C. finmarchicus [vertically integrated, presented in units of $\left.\log _{10}\left(1+\# / \mathrm{m}^{2}\right)\right]$ after data assimilation, with the same mapping area as Figure 3. Isobaths shown are 60,100 , and $200 \mathrm{~m}$.

Figure 6: Optimal initial fields for C. finmarchicus stages $\mathrm{N}_{3}$ to $\mathrm{C}_{6}$ [vertically integrated, presented in units of $\left.\log _{10}\left(1+\# / \mathrm{m}^{2}\right)\right]$. The first estimates of initial values outside the data area (white area in Figure 3) are zeros. Isobaths shown are 60 and $200 \mathrm{~m}$.

Figure 7: Inferred net sources/sinks of $\mathrm{N}_{3}$ (vertically integrated, presented in units of $\# \mathrm{~m}^{-2} \mathrm{~s}^{-1}$ ). Isobaths shown are 60 and $200 \mathrm{~m}$.

Figure 8: Computed monthly mean molting fluxes (vertically integrated, presented in units of \# $\left.\mathrm{m}^{-2} \mathrm{~s}^{-1}\right)$. Isobaths shown are 60 and $200 \mathrm{~m}$.

Figure 9: The spatial distribution of the inferred mortality rates $\left(\mathrm{d}^{-1}\right)$. Plot area is zoomed in on Georges Bank to show detail in that region. Mortality estimates are negligible in the off-bank areas in which concentrations are not constrained by observations. Isobaths shown are 60 and $200 \mathrm{~m}$.

Figure 10: Time series of mortality rates $\left(\mathrm{d}^{-1}\right)$ spatially averaged on GB.

Figure 11: Temporal mean (January-June) of spatially averaged mortality rates $\left(\mathrm{d}^{-1}\right)$ on GB. 
Figure 12: Computed convergence of the monthly-mean advective fluxes (vertically integrated, presented in units of $\# \mathrm{~m}^{-2} \mathrm{~s}^{-1}$ ). Isobaths shown are 60 and $200 \mathrm{~m}$.

Figure 13: Computed convergence of the monthly-mean diffusive fluxes (vertically integrated, presented in units of $\# \mathrm{~m}^{-2} \mathrm{~s}^{-1}$ ). Isobaths shown are 60 and $200 \mathrm{~m}$.

Figure 14: Temporally and spatially averaged term balances on GB. Here $\operatorname{Adv}($ ection $)=$ $-\nabla \cdot\left(\mathbf{V} C_{i}\right) ; \operatorname{Dif}($ fusion $)=\nabla \cdot\left(H K \nabla C_{i}\right) / H ; \operatorname{Ten}($ dency $)=\partial C_{i} / \partial t ; \operatorname{Mor}($ tality $)=\mu_{i} C_{i} ; \operatorname{Mol}($ ting flux, net $)=\mathrm{F}_{i-1}-\mathrm{F}_{i}, \mathrm{i}=2,3, \ldots, 10$. Values are presented on a $\log$ scale with units of $\log _{10}\left(1+\# \mathrm{~m}^{-3}\right.$ $\left.\mathrm{d}^{-1}\right)$. Blue bars represent negative values, red bars represent positive values. Gray bars represent standard deviations.

Figure 15: Temporally and spatially averaged term magnitudes on GB. Here $\operatorname{Adv}(v e c t i o n)=$ $\nabla \cdot\left(\mathbf{V} C_{i}\right) ; \operatorname{Dif}($ fusion $)=\nabla \cdot\left(H K \nabla C_{i}\right) / H ; \operatorname{Ten}($ dency $)=\partial C_{i} / \partial t ; \operatorname{Mor}($ tality $)=\mu_{i} C_{i} ; \operatorname{Mol}($ ting flux, net $)=\mathrm{F}_{i-1}-\mathrm{F}_{i}, \mathrm{i}=2,3, \ldots, 10$. Values are presented on a log scale with units of $\log _{10}\left(1+\# \mathrm{~m}^{-3} \mathrm{~d}^{-1}\right)$. Term magnitudes are shown as blue bars; gray bars represent standard deviations.

Figure 16: Temporal mean (January-June) of spatially averaged mortality rates $\left(\mathrm{d}^{-1}\right)$ on GB for the baseline solution (black bars as in Figure 11) and the solution in which all upstream sources were set to zero (gray bars; see text).

Figure 17: Cartoon schematic comparing the results of the baseline inversion with a sensitivity experiment in which all upstream sources of $C$. finmarchicus were set to zero. 


\begin{tabular}{|c|c|c|c|c|c|c|c|c|c|}
\hline Time Period & \multicolumn{9}{|c|}{ Stage } \\
\hline & $\mathrm{N}_{4}$ & $\mathrm{~N}_{5}$ & $\mathrm{~N}_{6}$ & $\mathrm{C}_{1}$ & $\mathrm{C}_{2}$ & $\mathrm{C}_{3}$ & $\mathrm{C}_{4}$ & $\mathrm{C}_{5}$ & $\mathrm{C}_{6}$ \\
\hline $\begin{array}{c}\text { January- } \\
\text { February }\end{array}$ & $57 \pm 24 \%$ & $54 \pm 23 \%$ & $52 \pm 23 \%$ & $58 \pm 24 \%$ & $55 \pm 23 \%$ & $59 \pm 24 \%$ & $57 \pm 24 \%$ & $53 \pm 23 \%$ & $51 \pm 23 \%$ \\
\hline March-April & $14 \pm 17 \%$ & $11 \pm 17 \%$ & $9 \pm 17 \%$ & $14 \pm 17 \%$ & $12 \pm 17 \%$ & $15 \pm 17 \%$ & $13 \pm 17 \%$ & $11 \pm 17 \%$ & $9 \pm 17 \%$ \\
\hline May-June & $17 \pm 12 \%$ & $14 \pm 11 \%$ & $13 \pm 11 \%$ & $17 \pm 12 \%$ & $15 \pm 11 \%$ & $18 \pm 12 \%$ & $16 \pm 11 \%$ & $14 \pm 11 \%$ & $12 \pm 11 \%$ \\
\hline
\end{tabular}

Table 1. Mean and standard deviation of the percentage increase in stage duration predicted by a temperature- and food-dependent model over that based on temperature alone. Only nodes on Georges Bank included in the computations.

\begin{tabular}{|l|c|c|c|c|c|}
\hline Stage & \multicolumn{5}{|c|}{ Term } \\
\hline & $\begin{array}{l}\text { Molting } \\
\mathrm{F}_{i-1}-\mathrm{F}_{i}\end{array}$ & $\begin{array}{c}\text { Mortality } \\
\mu_{i} C_{i}\end{array}$ & $\begin{array}{c}\text { Advection } \\
-\nabla \cdot\left(\mathbf{V} C_{i}\right)\end{array}$ & $\begin{array}{c}\text { Diffusion } \\
\nabla \cdot\left(H K \nabla C_{i}\right) / H\end{array}$ & $\begin{array}{c}\text { Tendency } \\
\partial C_{i} / \partial t\end{array}$ \\
\hline $\mathrm{C}_{2}$ & 0.9661 & -2.2759 & 0.1227 & -0.0769 & -1.2640 \\
\hline $\mathrm{C}_{3}$ & -1.4326 & -1.1062 & 0.1061 & -0.0804 & -2.5131 \\
\hline $\mathrm{C}_{4}$ & -2.2027 & -1.8964 & 0.0072 & -0.1429 & -4.2348 \\
\hline $\mathrm{C}_{5}$ & 3.0676 & -5.1040 & 0.0739 & -0.1368 & -2.0993 \\
\hline $\mathrm{C}_{6}$ & 6.1338 & -6.3514 & -0.1780 & -0.0883 & -0.4839 \\
\hline
\end{tabular}

Table 2. Space-time averaged values of the biological and physical controls of $\mathrm{C}_{2}-\mathrm{C}_{5}$ on the Crest between May-June. Units are \# $\mathrm{m}^{-3} \mathrm{~d}^{-1}$. 


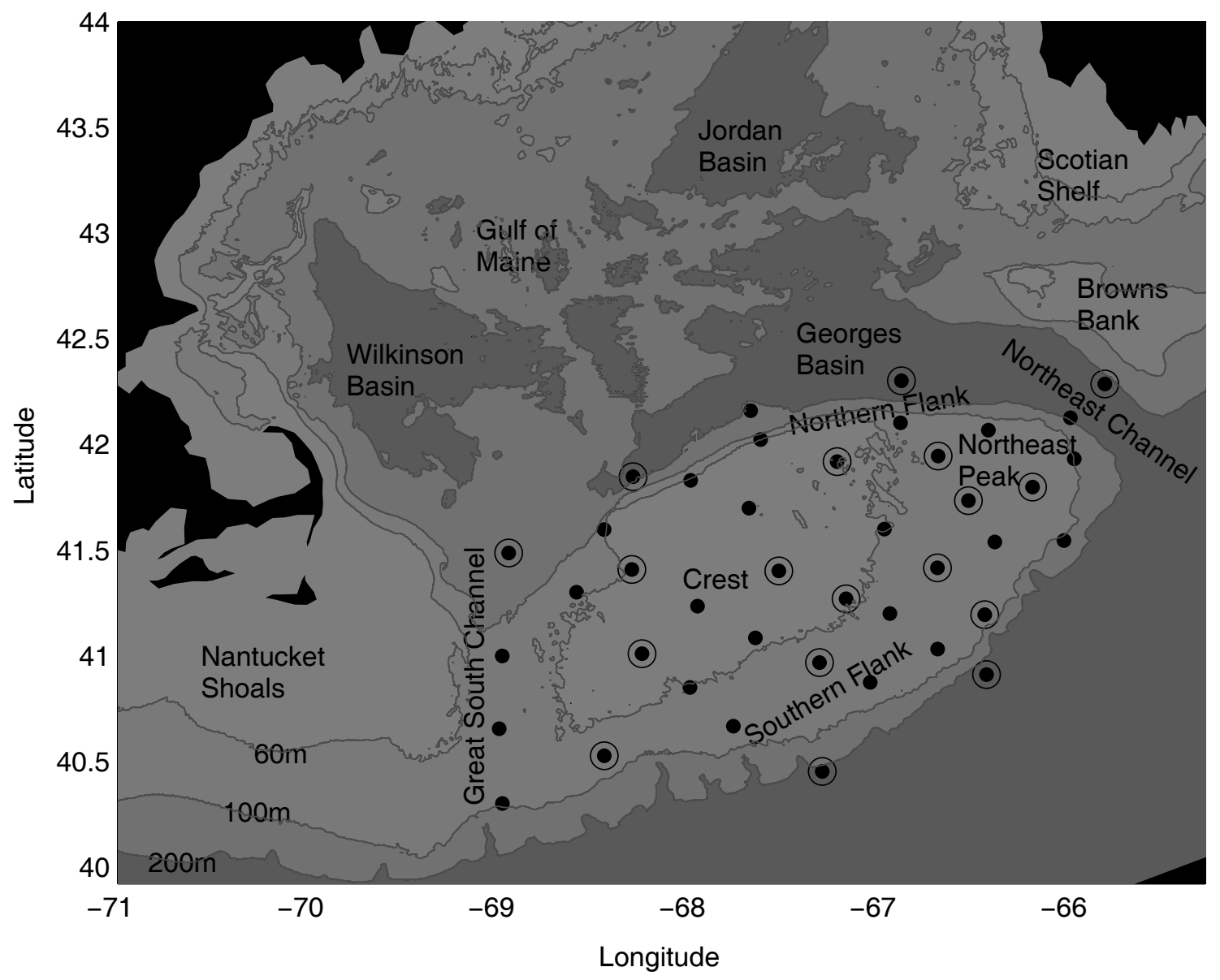

Figure 1 


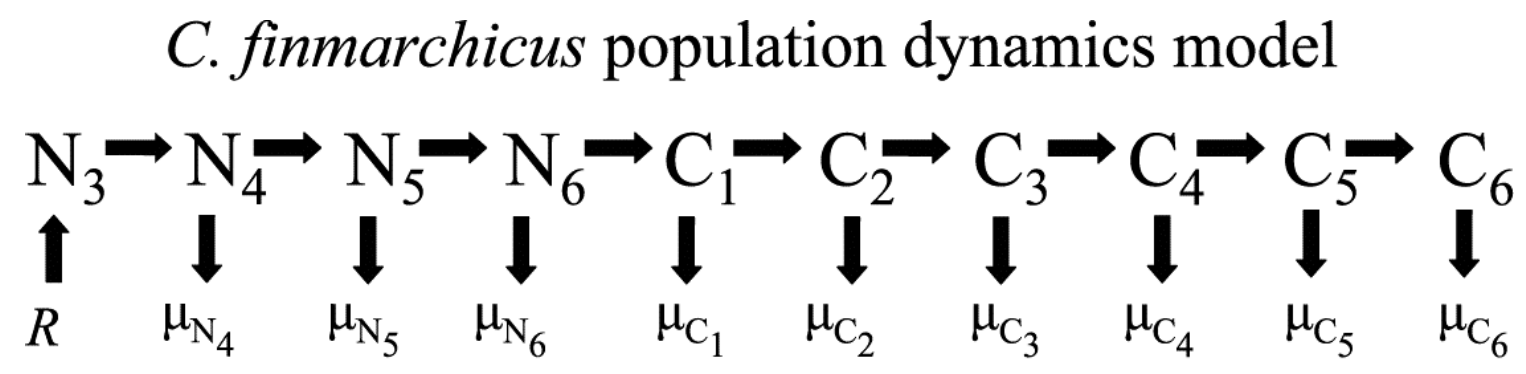

Specified

$\begin{aligned} & \mathrm{N}_{3}-\mathrm{C}_{6} \text { on bank } \\ & \text { molting flux }\end{aligned}$
$\begin{aligned} & \text { inferred } \\ & N_{3}-C_{6} \text { off-bank }\end{aligned}$
$\begin{aligned} & \text { computed from } \mathrm{T} \\ & \text { sources of } \mathrm{N}_{3}\end{aligned}$
mortality

\begin{tabular}{|l|l|l|l|}
\hline Component & Source & Temporal Resolution & Spatial Coverage \\
\hline Hydrodynamic model & $\begin{array}{l}\text { Dartmouth } \\
\text { Climatology }\end{array}$ & Bi-monthly & Regional \\
\hline C. finmarchicus $\mathrm{N}_{3}-\mathrm{C}_{6}$ & $\begin{array}{l}\text { GLOBEC } \\
1995-1999\end{array}$ & Monthly & Georges Bank \\
\hline Chlorophyll & $\begin{array}{l}\text { MARMAP } \\
1977-1987\end{array}$ & Bi-monthly & Regional \\
\hline
\end{tabular}

Figure 2 


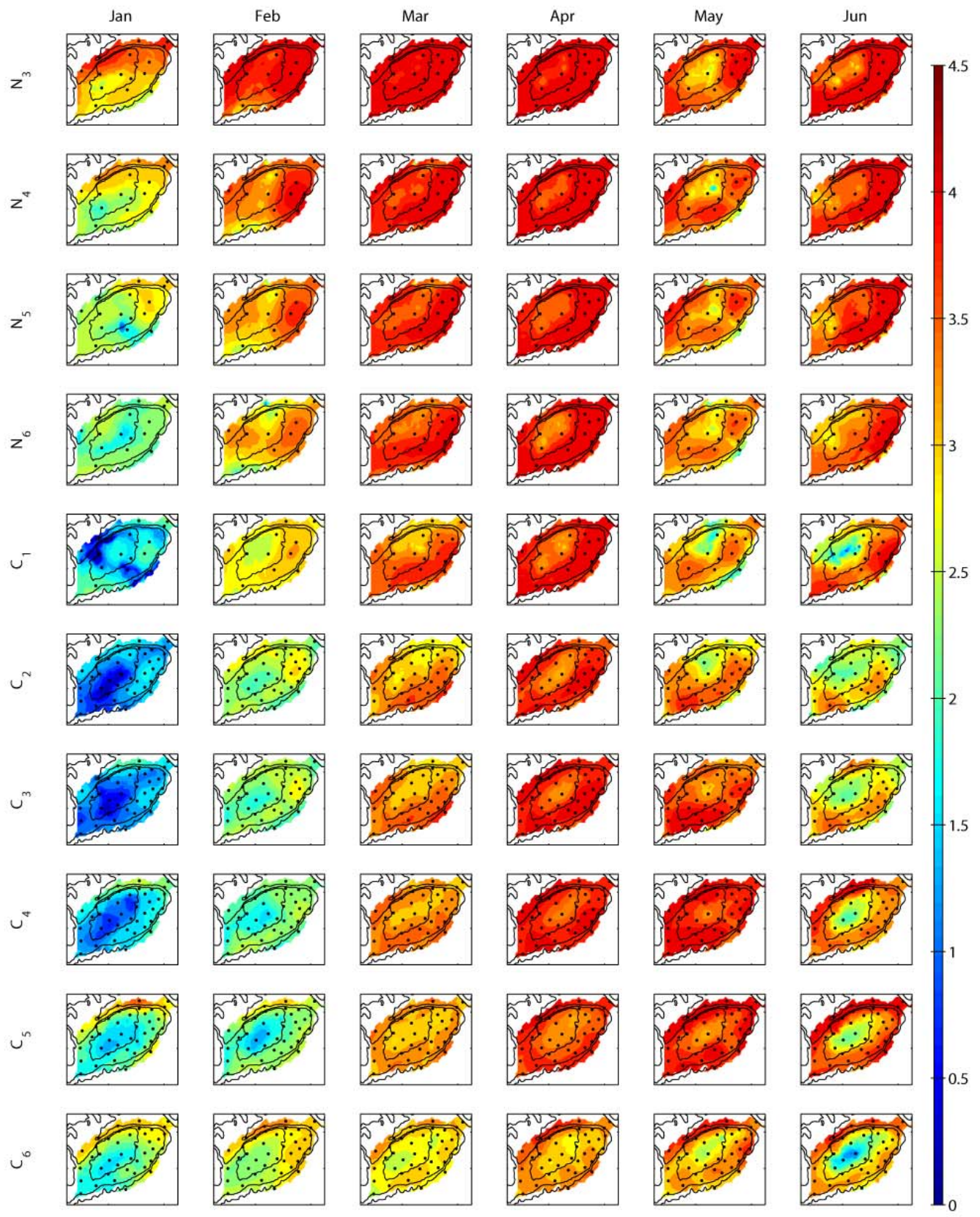

Figure 3 


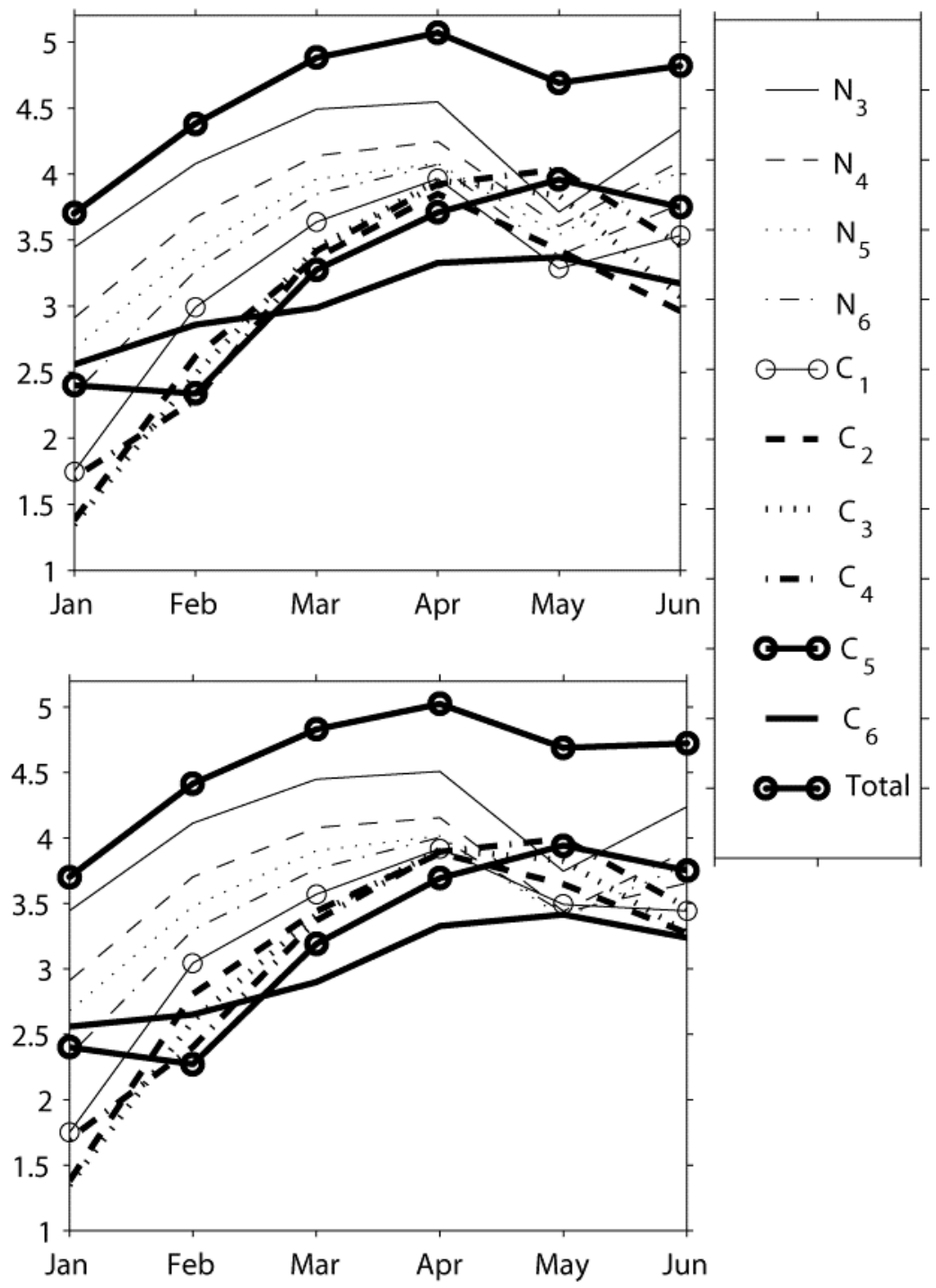

Figure 4 

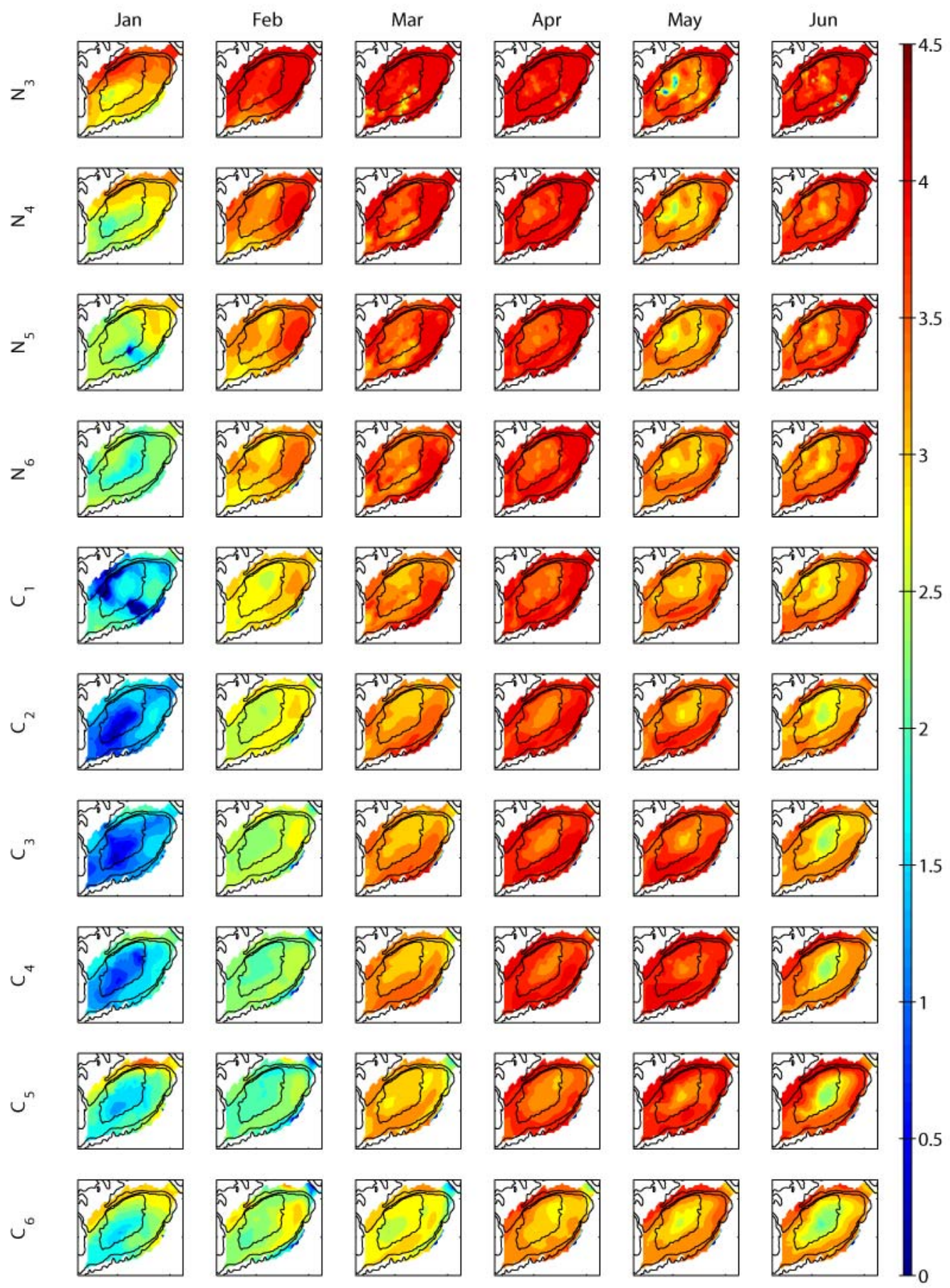

Figure 5 

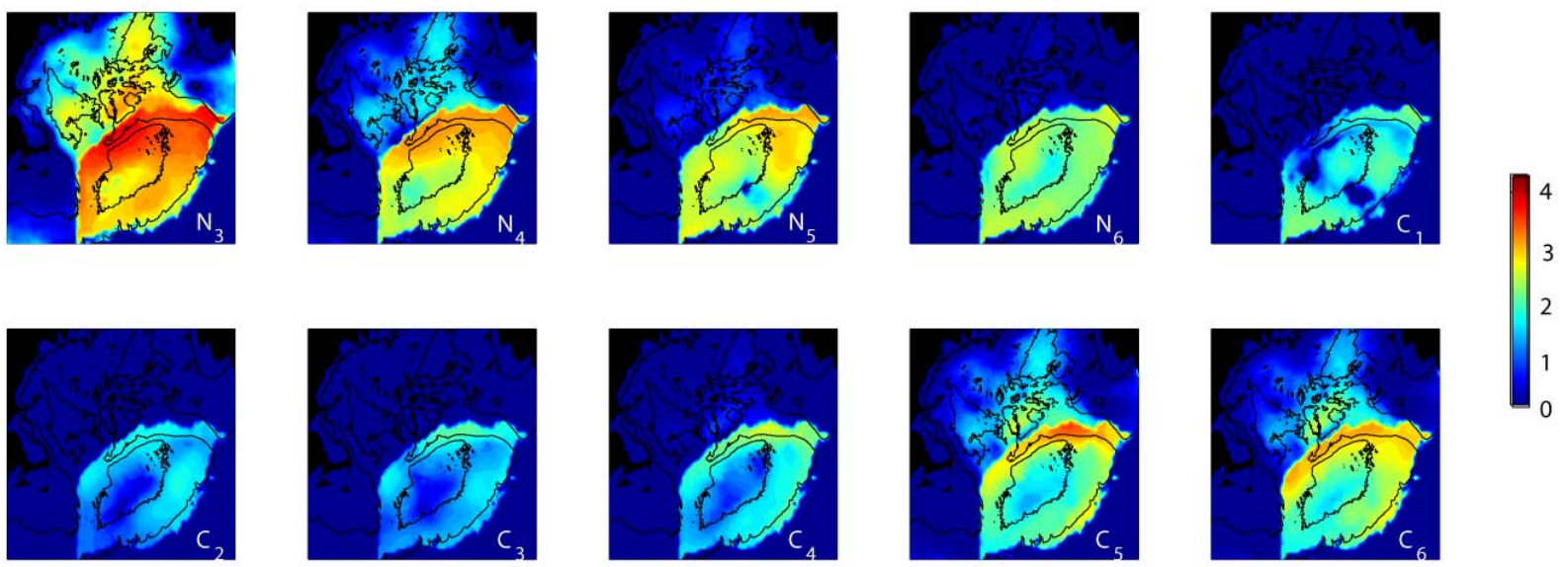

Figure 6
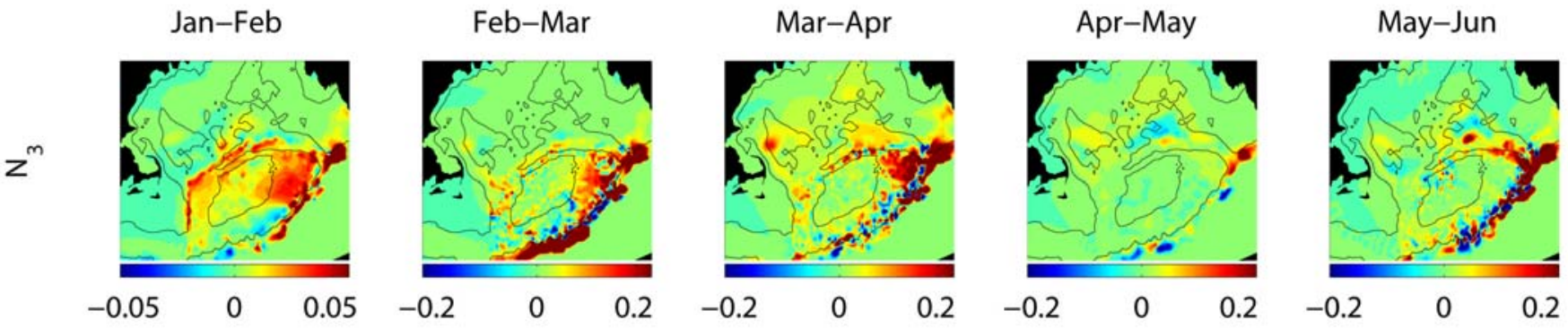

Figure 7 

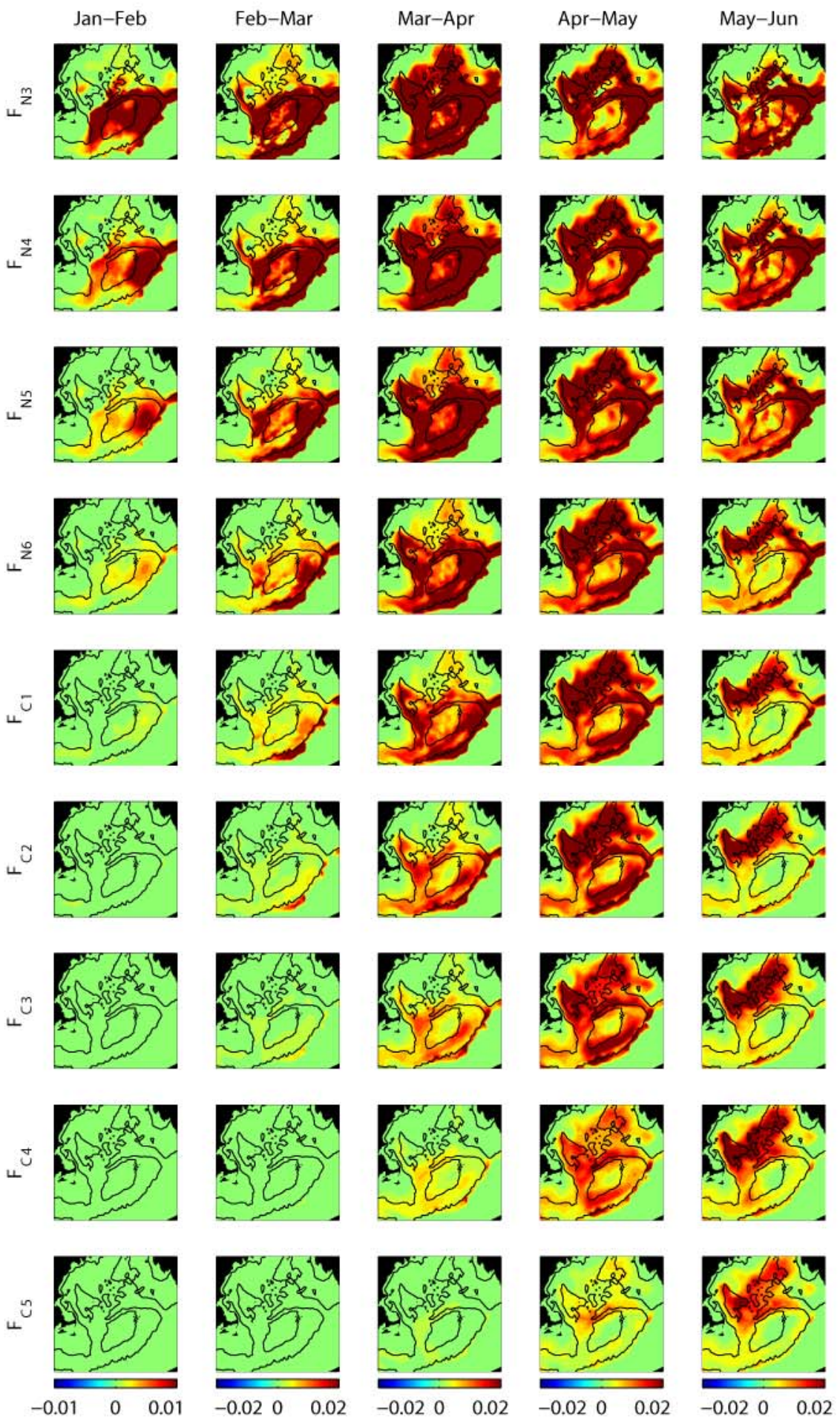

Molting fluxes $\left(\# \mathrm{~m}^{-2} \mathrm{~s}^{-1}\right)$

Figure 8 

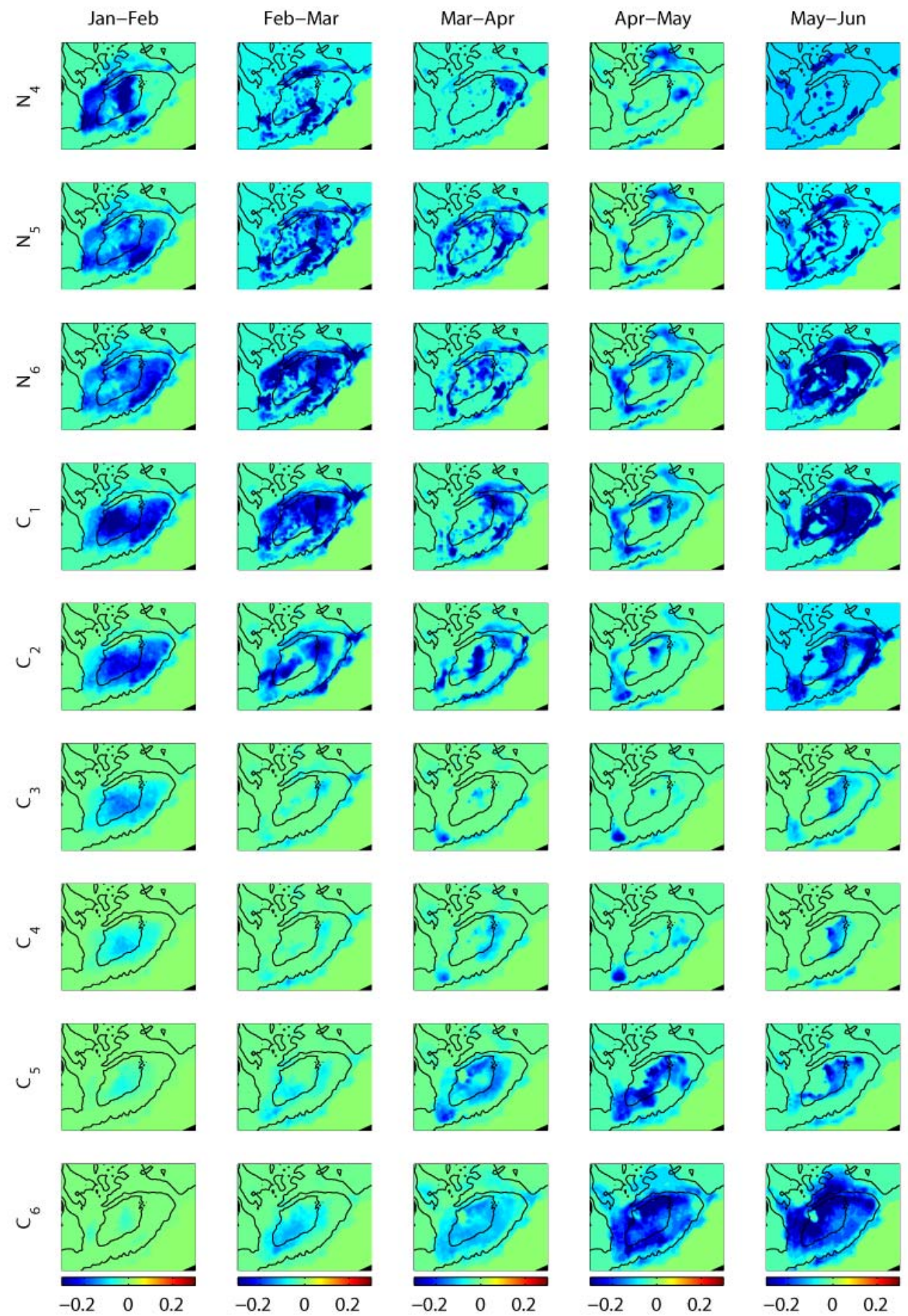

Mortality Rates $\left(\mathrm{d}^{-1}\right)$

Figure 9 


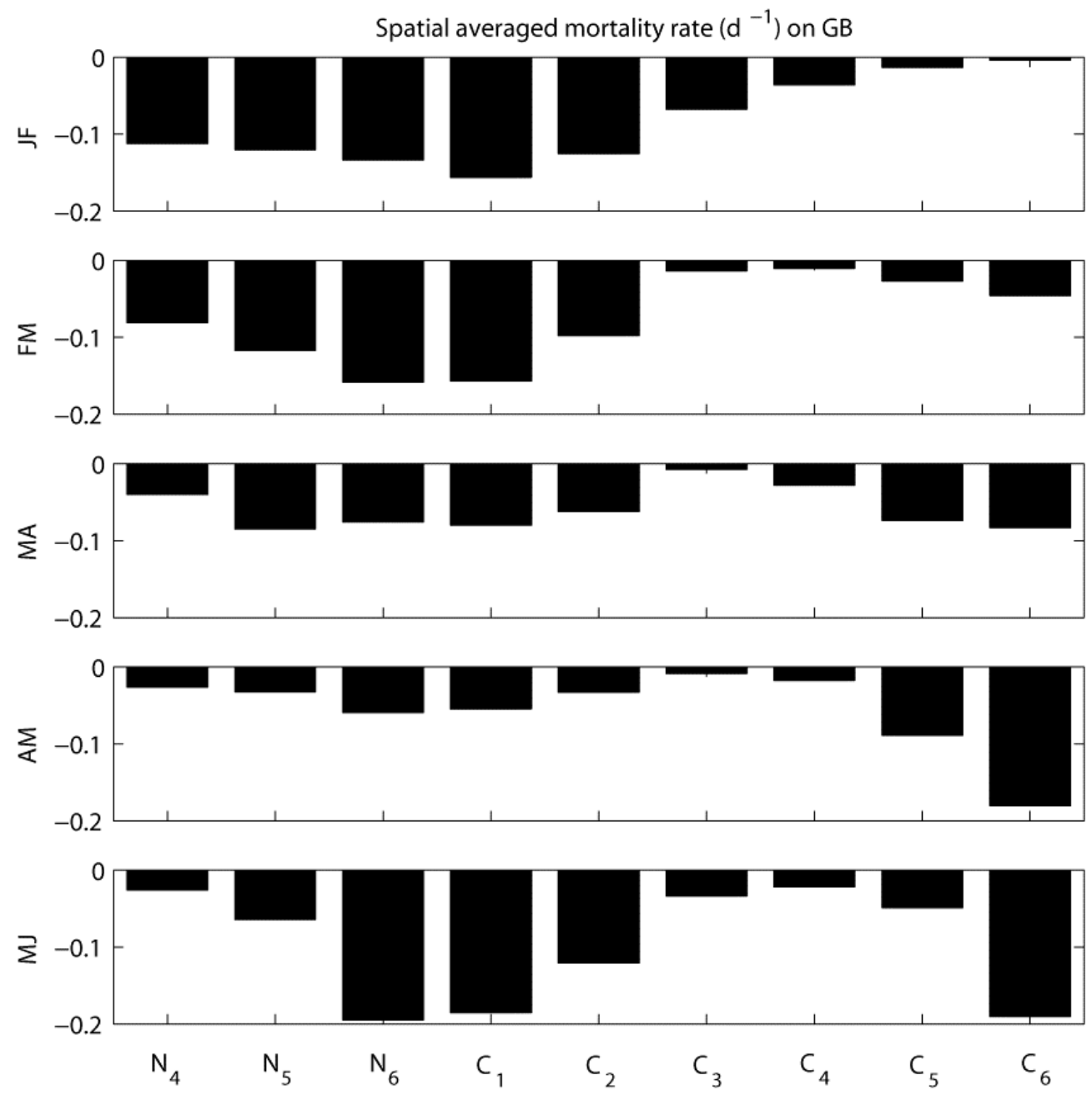

Figure 10 


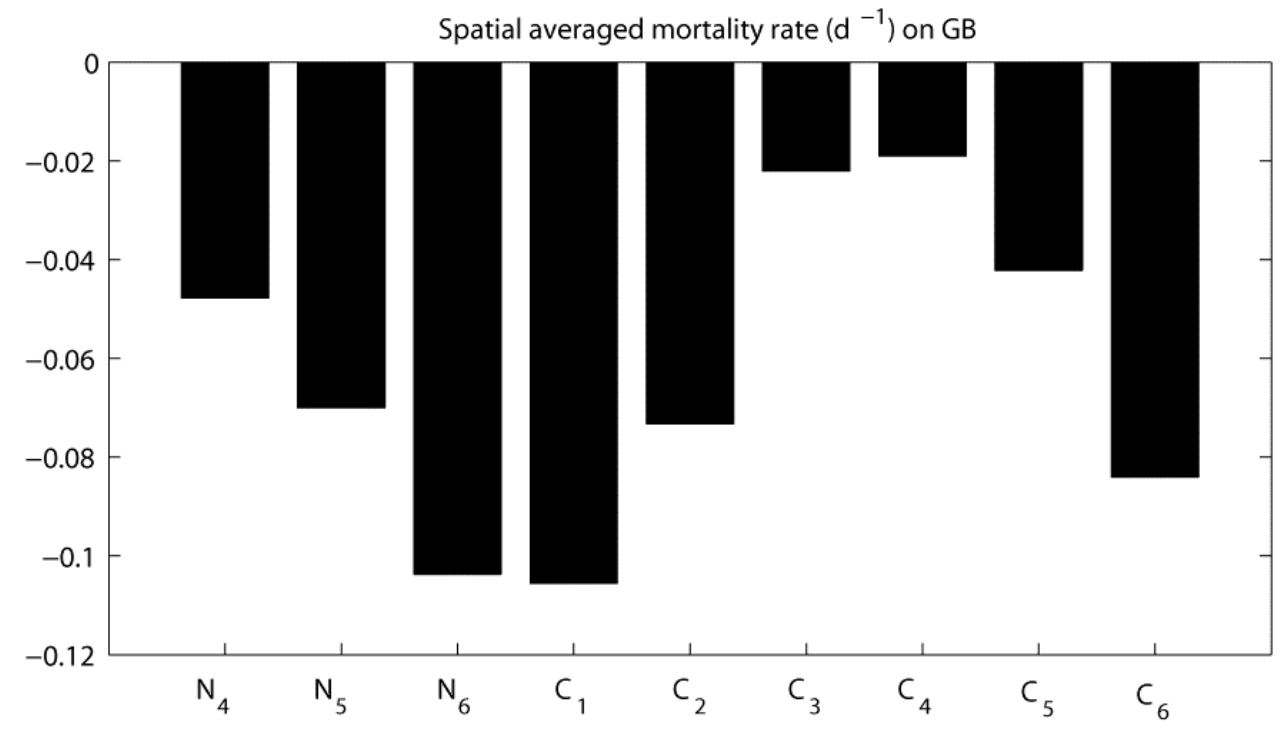

Figure 11 

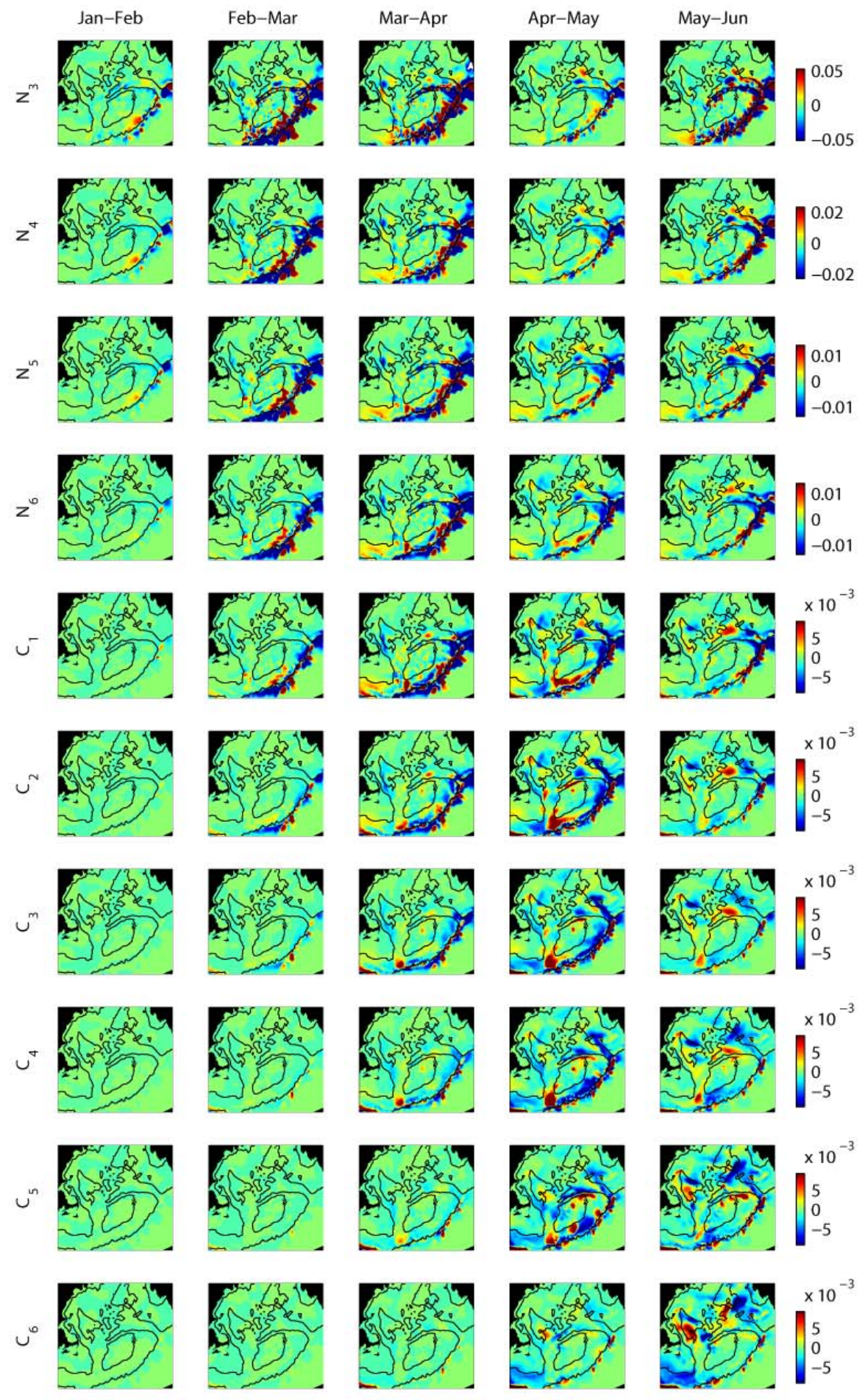

Figure 12 

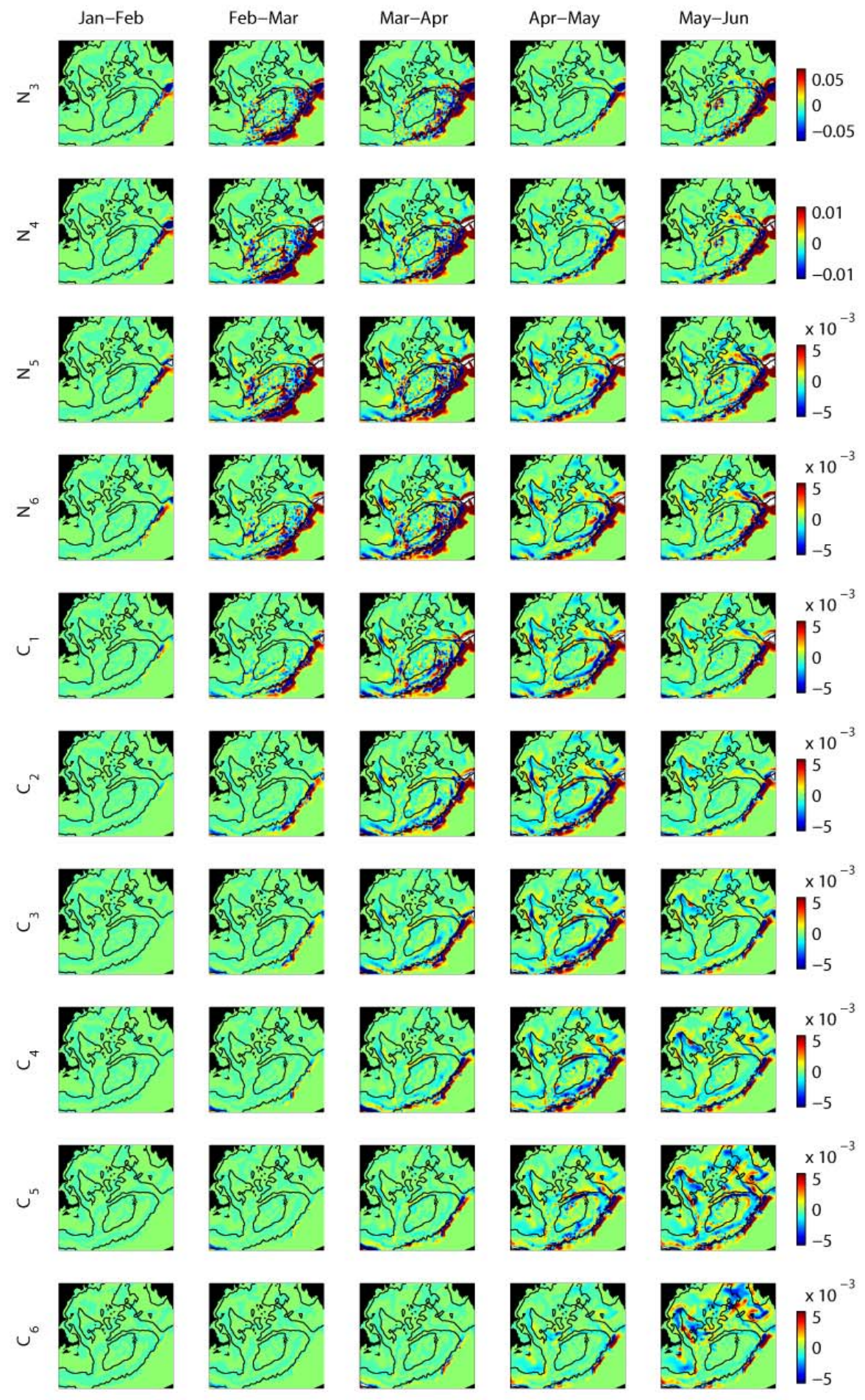

Figure 13 

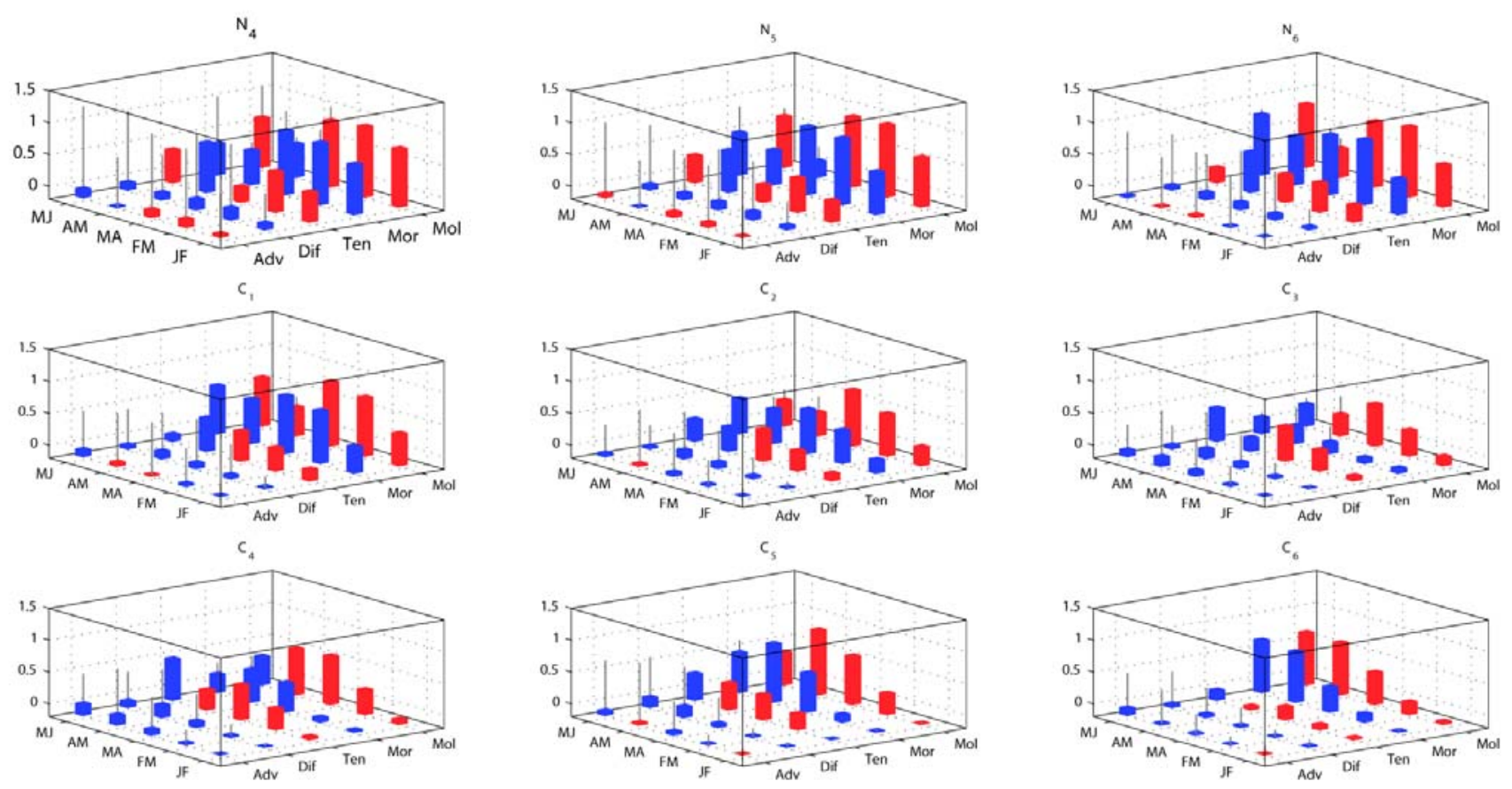

Figure 14
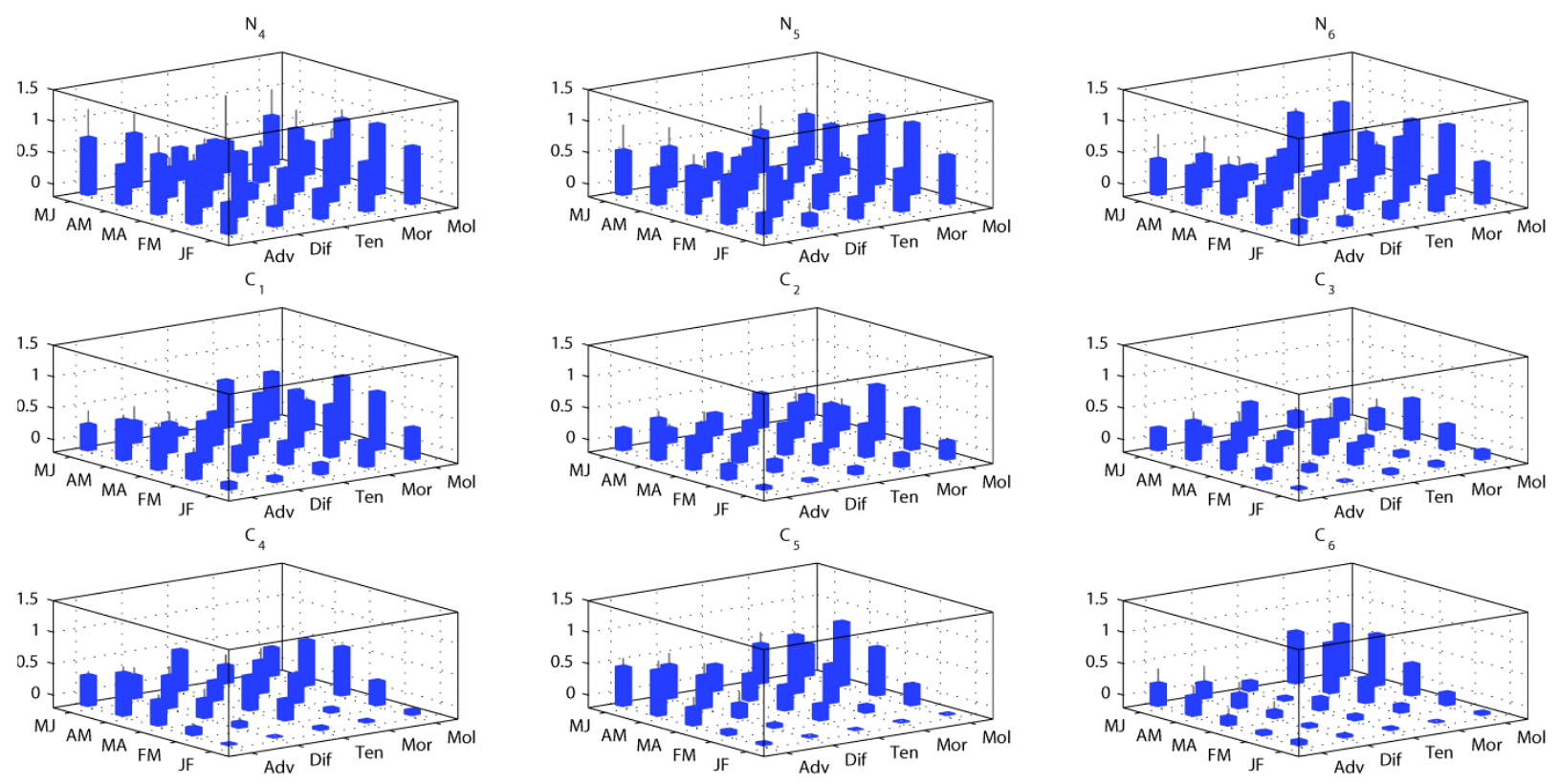

Figure 15 


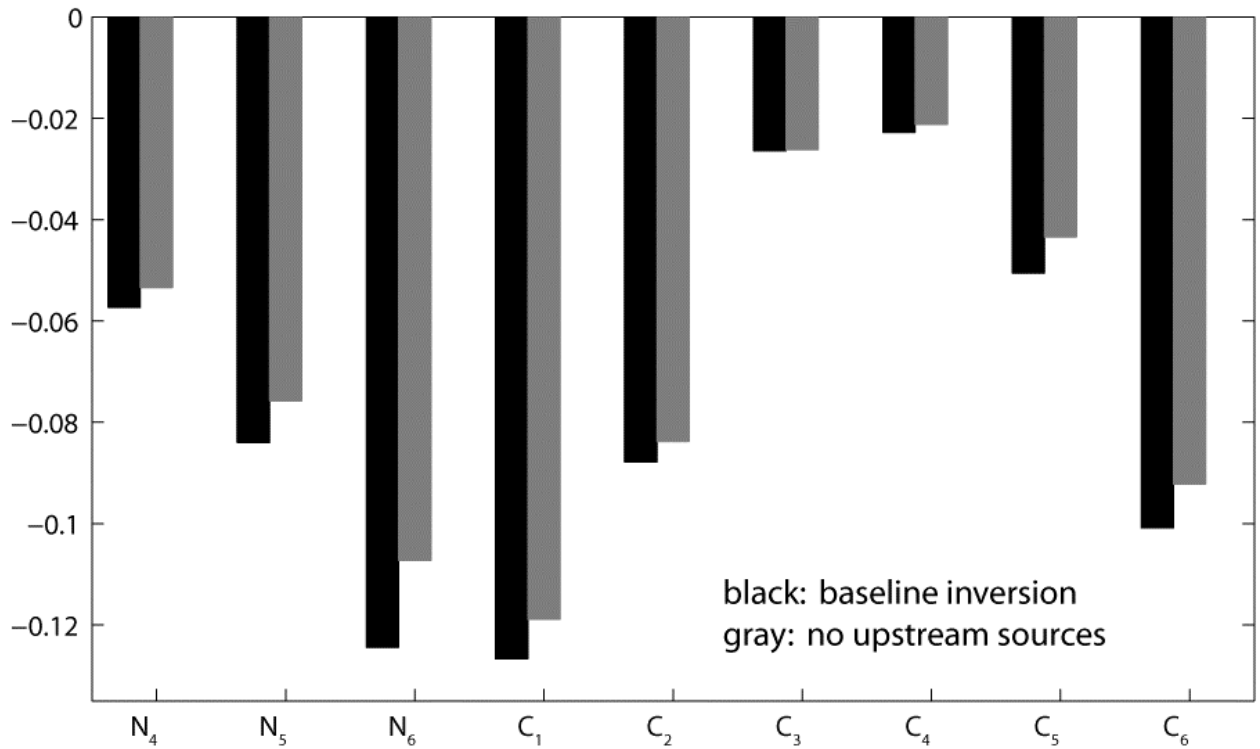

Fig 16 
Biological control of the vernal population increase of $C$. finmarchicus on Georges Bank

Realistic Solution

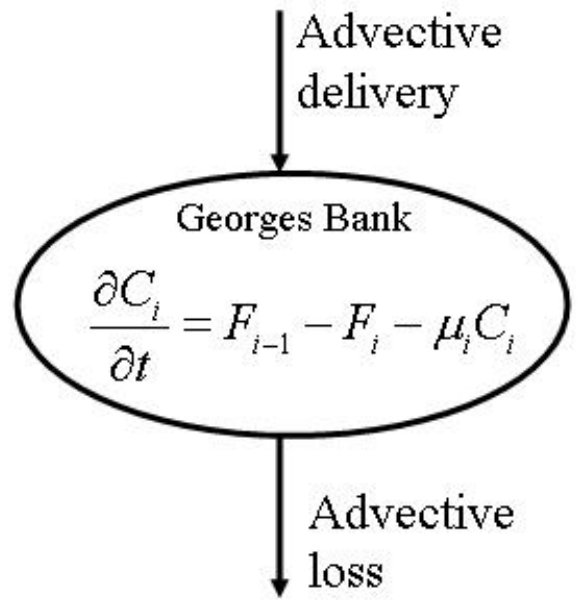

Sensitivity Experiment

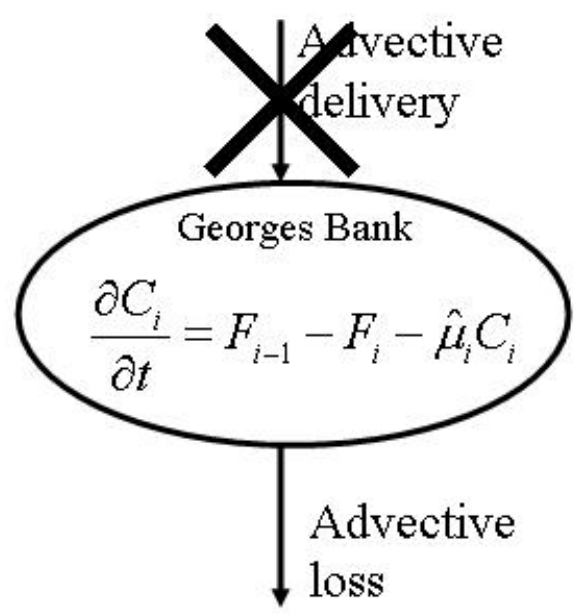

$\hat{\mu}_{i}$ only slightly smaller than $\mu_{i}$

Fig 17 